\title{
A glycosylphosphatidylinositol-anchored $\alpha$-amylase encoded by amyD contributes to a decrease in the molecular mass of cell wall $\alpha-1,3$-glucan in Aspergillus nidulans
}

Ken Miyazawa ${ }^{1,2}$, Takaaki Yamashita ${ }^{1}$, Ayumu Takeuchi ${ }^{1}$, Yuka Kamachi ${ }^{1}$, Akira Yoshimi ${ }^{3,4}$,

$7 \quad{ }^{1}$ Laboratory of Applied Microbiology, Department of Microbial Biotechnology, Graduate

8 School of Agricultural Sciences, Tohoku University, Sendai, Japan

$9{ }^{2}$ Laboratory of Filamentous Mycoses, Department of Fungal Infection, National Institute of

Infectious Diseases, Tokyo, Japan

$11{ }^{3}$ Laboratory of Environmental Interface Technology of Filamentous Fungi, Graduate School

12 of Agriculture, Kyoto University, Kyoto, Japan

${ }^{4}$ ABE-Project, New Industry Creation Hatchery Center, Tohoku University, Sendai, Japan

${ }^{5}$ Department of Biochemical Engineering, Graduate School of Engineering, Yamagata

15 University, Yonezawa, Japan

$16{ }^{6}$ Food Microbiology Unit, School of Food and Agricultural Sciences, Miyagi University,

17 Sendai, Japan

$18{ }^{7}$ Genome Biotechnology Laboratory, Kanazawa Institute of Technology, Hakusan, Japan

$19{ }^{8}$ Department of Applied Life Science, The United Graduate School of Agricultural Science,

20 Tokyo University of Agriculture and Technology, Fuchu, Japan

$21{ }^{9}$ Department of Microbial Resources, Graduate School of Agricultural Science, Tohoku

22 University, Sendai, Japan

23 *Correspondence: keietsu.abe.b5@tohoku.ac.jp

24 Key words: cell wall, filamentous fungi, Aspergillus nidulans, $\alpha$-1,3-glucan,

25 glycosylphosphatidylinositol-anchored protein, $\alpha$-amylase

Running title: $\alpha-1,3-$ Glucan biosynthesis regulated by AmyD $\alpha-1,3-$ Glucan is one of the main polysaccharides in the cell wall of Aspergillus nidulans. We previously revealed that it plays a role in hyphal aggregation in liquid culture, and that its molecular mass $(\mathrm{MM})$ in an agsA-overexpressing $\left(a g s A^{O E}\right)$ strain was larger than that in an ags $B$-overexpressing $\left(\operatorname{ags} B^{O E}\right)$ strain. The mechanism that regulates the MM of $\alpha-1,3$-glucan 
is poorly understood. Although the gene $a m y D$, which encodes glycosyl-phosphatidylinositol (GPI)-anchored $\alpha$-amylase (AmyD), is involved in the biosynthesis of $\alpha$-1,3-glucan in $A$. nidulans, how it regulates this biosynthesis remains unclear. Here we constructed strains with disrupted $a m y D(\triangle a m y D)$ or overexpressed $\operatorname{amy} D\left(a m y D^{O E}\right)$ in the genetic background of the ABPU1 (wild-type), $a g s A^{O E}$, or $a g s B^{O E}$ strain, and characterized the chemical structure of $\alpha$ 1,3-glucans in the cell wall of each strain, focusing on their MM. The MM of $\alpha-1,3$-glucan from the $\operatorname{ags}_{S} O E a m y D^{O E}$ strain was smaller than that in the parental $\operatorname{ags} B^{O E}$ strain. In addition, the MM of $\alpha-1,3$-glucan from the $\operatorname{ags} A^{O E} \triangle a m y D$ strain was greater than that in the $\operatorname{agsA}^{O E}$ strain. These results suggest that AmyD is involved in decreasing the MM of $\alpha-1,3-$ glucan. We also found that the C-terminal GPI-anchoring region is important for these functions.

\section{Introduction}

The fungal cell wall, composed mainly of polysaccharides, is essential for the survival of the fungus (Latgè et al., 2017). It has recently been understood that the cell wall is a highly dynamic structure; cell-wall components are synthesized by synthases and then reconstructed by glycosyltransferases to form a proper cell-wall architecture (Latgè and Beauvais, 2014;Latgè et al., 2017). The cell wall of filamentous fungi contains $\alpha$-glucans, $\beta$-glucans, chitin, and galactomannan. Some fungi form an extracellular matrix, which includes secretory polysaccharides such as galactosaminogalactan (Sheppard and Howell, 2016;Yoshimi et al., 2016; Miyazawa et al., 2019). Cell-wall polysaccharides of some Aspergillus species can be fractionated into alkali-soluble and alkali-insoluble fractions (Fontaine et al., 2000;Yoshimi et al., 2013; Dichtl et al., 2015;Zhang et al., 2017b). The alkali-soluble fraction contains mainly $\alpha-1,3$-glucan with interconnecting $\alpha$-1,4-linkage and some galactomannan (Bernard and Latge, 2001;Latgè, 2010). The alkali-insoluble fraction is composed of chitin, $\beta$-1,6-branched ß-1,3-glucan, and galactomannan (Fontaine et al., 2000;Bernard and Latge, 2001).

$$
\text { In the human pathogenic dimorphic yeast Histoplasma capsulatum and the rice blast }
$$
fungus Magnaporthe grisea, $\alpha-1,3$-glucan functions as a stealth factor that prevents host immune recognition and consequently contributes to the establishment of invasion or infection (Rappleye et al., 2004;Rappleye et al., 2007;Fujikawa et al., 2009;Fujikawa et al., 2012). In addition, the pathogenesis of an $\alpha-1,3$-glucan-deficient strain is decreased in murine models infected with Aspergillus fumigatus (Henry et al., 2012;Beauvais et al., 2013).

Recently, $\alpha$-1,3-glucan was reported to stimulate the polarization of regulatory T-cells by inducing programmed death-ligand 1 expression on human dendritic cells (Stephen-Victor et 
66

67

68

69

70

al., 2017). Fontaine et al. (2010) revealed that $\alpha-1,3$-glucan has adhesivity when the conidia of A. fumigatus germinate.

Grün et al. (2005) analyzed the detailed chemical structure of $\alpha$-glucan in the cell wall of the fission yeast Schizosaccharomyces pombe and found that its molecular mass (MM) is $42 \square 600 \pm 5 \square 200$, which is equivalent to a degree of polymerization of $263 \pm 32$ (Grün et al., 2005). The $\alpha$-glucans derived from $S$. pombe are composed of two chains of $\approx 120$ residues of 1,3-linked $\alpha$-glucose with 12 residues of 1,4-linked $\alpha$-glucose at the reducing ends (Grün et al., 2005). In Aspergillus wentii, the water-insoluble (alkali-soluble) glucan has a MM of $\approx 850 \square 000$ and consists of 25 subunits (200 residues each) of $\alpha$-1,3-glucan separated by short spacers composed of 1,4-linked $\alpha$-glucan (Choma et al., 2013).

Aspergillus species have several $\alpha-1,3$-glucan synthase genes: two in Aspergillus nidulans (agsA and agsB), three in A. fumigatus (AGS1-3) and Aspergillus oryzae (agsA-C), and five in Aspergillus niger (ags $A-E$ ). Disruptants of A. fumigatus that lack a single gene or all three genes have been constructed (Beauvais et al., 2005;Maubon et al., 2006;Henry et al., 2012); these strains lack $\alpha-1,3$-glucan in the cell wall and are less pathogenic (Beauvais et al., 2013). In $A$. oryzae, ags $B$ (orthologous to $A$. nidulans ags $B$ ) is the primary $\alpha-1,3$-glucan synthase gene (Zhang et al., 2017b). An A. oryzae disruptant lacking all three genes loses its cell-wall $\alpha$-1,3-glucan and forms small hyphal pellets under liquid culture conditions (Miyazawa et al., 2016). In A. niger, the expression of agsA (orthologous to A. fumigatus $A G S 3$; no orthologue in A. nidulans) and agsE (orthologous to A. nidulans agsB) is upregulated in the presence of stress-inducing compounds in the cell wall (Damveld et al., 2005). In the kuro (black) koji mold Aspergillus luchuensis, disruption of agsE (orthologous to $A$. nidulans agsB) improves the protoplast formation (Tokashiki et al., 2019). Recently Uechi et al. revealed that $A$. luchuensis agsB (no orthologue in A. nidulans) plays a role in nigeran synthesis (Uechi et al., 2021). In A. nidulans, $\alpha$-1,3-glucan in vegetative hyphae is synthesized mainly by AgsB (Yoshimi et al., 2013;He et al., 2014). The hyphae of a mutant deficient in $\alpha$-1,3-glucan became fully dispersed, showing that $\alpha$-1,3-glucan is a hyphal aggregation factor (Yoshimi et al., 2013;He et al., 2014). We recently constructed strains overexpressing $\operatorname{ags} A\left(\operatorname{ags}_{s}{ }^{O E}\right)$ and $\operatorname{ags}_{s}\left(a_{g s} B^{O E}\right)$ in the genetic background of, respectively, $a g s B$ and $a g s A$ disruptants. The peak MM of alkali-soluble glucan from $a g s A^{O E}$ was $1 \square 480 \square 000 \pm 80 \square 000$, which was four times that from the $a g s B^{O E}$ (MM, $372 \square 000 \pm$ 47 $\square 000$ ) (Miyazawa et al., 2018). The alkali-soluble glucan derived from these strains contains several 1,4-linked spacer structures interlinking the $\alpha$-1,3-glucan subunits, which each contain 200 glucose residues (Miyazawa et al., 2018). 
Outside of A. fumigatus, A. nidulans ags $B$ and its orthologues are clustered with two $\alpha$ -

101

102

103

104

105

106

107

108

109

110

111

112

113

114

115

116

117

118

119

120

121

122

123

124

125

126

127

128

129

130

131 amylase-encoding genes (amyD and amyG in A. nidulans) (He et al., 2014; Yoshimi et al., 2017; Miyazawa et al., 2020). The amy $G$ gene encodes an intracellular $\alpha$-amylase and is crucial for $\alpha$-1,3-glucan synthesis (He et al., 2014). The amyD gene in A. nidulans encodes glycosylphosphatidylinositol (GPI)-anchored $\alpha$-amylase. He et al. (2014) reported that $\alpha$-1,3glucan contents increased by $50 \%$ in an amyD-disrupted $(\triangle a m y D)$ strain and halved in an $a m y D$-overexpressing $(a c t A(\mathrm{p})-a m y D)$ strain, suggesting that $a m y D$ has a repressive effect on $\alpha-1,3$-glucan synthesis. In addition, He et al. (2017) analyzed the chronological changes of $\alpha$ 1,3 -glucan contents under liquid culture conditions. Whereas the amount of $\alpha$-1,3-glucan in strains that overexpressed the $\alpha-1,3$-glucanase-encoding gene ( $m u t A$ or $a g n B$ ) was decreased after $20 \mathrm{~h}$ from inoculation, the amount of $\alpha-1,3$-glucan in the cell wall of the $a m y D^{O E}$ strain was half that of the wild-type strain from the initial stage of cultivation (He et al., 2017). $\mathrm{He}$ et al. (2017) suggested that AmyD decreased the amount of $\alpha-1,3$-glucan in the cell wall by a mechanism independent of the effect of $\alpha-1,3$-glucanase. The enzymatic characteristics of $A$. niger AgtA, which is encoded by an orthologue of $A$. nidulans amyD, have been reported (van der Kaaij et al., 2007). Although AgtA in A. niger barely hydrolyzed $\alpha-1,3$-glucan, it had relatively high transglycosylation activity on donor substrates with maltooligosaccharides (van der Kaaij et al., 2007). Overall, AmyD seems to indirectly decrease the amount of $\alpha-1,3-$ glucan in the cell wall, but the detailed mechanism is still unknown.

Here, in a study of the function of $a m y D$ in $\alpha-1,3$-glucan biosynthesis in $A$. nidulans, we constructed strains with overexpression or disruption of $a m y D$ in the genetic backgrounds of the wild-type, $\operatorname{ags} A^{O E}$, and $a g s B^{O E}$. We performed several chemical analyses of $\alpha-1,3$-glucan derived from the strains, looking in particular at its MM, and examined the role of $a m y D$ in controlling the MM of $\alpha-1,3$-glucan in the cell wall.

\section{Materials and Methods}

\section{Strains and growth media}

Strains are listed in Table 1. Czapek-Dox (CD) medium was used as the standard culture, as described previously (Fujioka et al., 2007;Miyazawa et al., 2018).

\section{Construction of the ags $A$ - and ags $B$-overexpressing strains}

We newly constructed $a g s A^{O E}$ and $a g s B^{O E}$ strains for this study. To generate $a g s A^{O E}$, pAPyTagsA plasmids (Miyazawa et al., 2018) were digested with NotI and transformed into a disrupted $\operatorname{ags} B(\triangle a g s B)$ strain (Fig. S1A). Correct integration of agsA overexpression 
132 cassettes was confirmed by PCR (Fig. S1B). To generate $\operatorname{ags} B^{O E}$, the disrupted $\operatorname{ags} A\left(\operatorname{\Delta ags}_{S}\right)$

133 strain was first generated using the Cre/loxP marker recycling system (Zhang et al., 2017a).

134 The pAPG-cre/DagsA plasmid (Miyazawa et al., 2018) was digested with EcoRI and

135 transformed into the ABPU1 $\left(\arg B^{+}\right)$strain. Candidate strains were selected on CD medium

136 without uridine and uracil, and then cultured on CD medium with uridine and uracil and $1 \%$

137 xylose to induce Cre expression (Fig. S1C). Strains that required uridine and uracil were

138 isolated, and then replacement of the agsA gene was confirmed by PCR (Fig. S1D). The

139 pAPyT-agsB plasmid was digested with NotI and transformed into the $\triangle a g s A$ strain (Fig.

$140 \mathrm{~S} 1 \mathrm{E})$. Correct integration of $a g s B$ overexpression cassettes was confirmed by PCR (Fig. S1B).

\section{Construction of the $a m y D^{O E}$ strain}

142 The $a m y D^{O E}$ strain was constructed by replacing the native promoter with the constitutive tefl

143 promoter. The sequences of the primers are listed in Table S1. To generate $a m y D^{O E}$, the

144 plasmid pAPT-amyD was constructed (Fig. S2A). The 5'-non-coding region (amplicon 1) and

145 the coding region (amplicon 2) of $a m y D$ were amplified from A. nidulans ABPU1 genomic

146 DNA. The pyrG marker (amplicon 3) was amplified from the pAPG-cre/DagsA plasmid. The

147 tefl promoter (amplicon 4) was amplified from the pAPyT-agsB plasmid. The four amplicons

148 and a SacI-digested pUC19 vector were fused using an In-Fusion HD Cloning Kit (Clontech

149 Laboratories, Inc., Mountain View, CA, USA). The resulting plasmid was digested with SacI,

150 and transformed into the ABPU1 $\left(\arg B^{+}\right), a g s A^{O E}$, and $\operatorname{ags} B^{O E}$ strains (Fig. S2B). Correct

151 integration of the cassette was confirmed by PCR (Fig. S2C).

\section{Disruption of the amyD gene}

153 In the first round of PCR, gene fragments containing the 5'-non-coding region (amplicon 1)

154 and the coding region (amplicon 2) of amyD were amplified from ABPU1 genomic DNA, and

155 the pyrG gene (amplicon 3) was amplified from A. oryzae genomic DNA (Fig. S2D). The

156 three resulting fragments were gel-purified and fused into a disruption cassette in the second

157 round of PCR. The resulting PCR product was gel-purified and transformed into the ABPU1

$158\left(\arg B^{+}\right), a g s A^{O E}$, and $a g s B^{O E}$ strains (Fig. S2E). Replacement of the $a m y D$ gene was

159 confirmed by PCR (Fig. S2F).

160 Expression of complementary amy $D$ genes

161 The sequences of the primers are listed in Table S1. A GPI-anchor modification site, the $\omega$ -

162 site, was predicted with the GPI Prediction Server v. 3.0 (https://mendel.imp.ac.at/gpi/

163 gpi_server.html), and the best score for the $\omega$-site was Asn535 of AmyD. To remove the GPI 
164 anchor of AmyD, 54 nucleotides corresponding to the 18 amino acid residues from Asn535 in

165 AmyD were deleted from the authentic amyD gene (Fig. S3A). To create complementary

166 genes that have full-length open reading frames of either $a m y D$ or the gene without the GPI

167 anchor-coding region, the plasmids pAHT-amyD, pAHdPT-amyD, pAHT-amyD $(\Delta \mathrm{GPI})$, and

168 pAHdPT-amyD( $\triangle$ GPI) were first constructed (Fig. S3A). To construct pAHT-amyD, primers

169 IF-Ptef1-hph-Fw and IF-amyD-up-hph-Rv were amplified by PCR using pAPT-amyD as a

170 template (amplicon 1). The hygromycin-resistance gene $h p h$ (amplicon 2) was amplified with

171 primers 397-5 and 397-3 from pSK397 (Krappmann et al., 2006). The two amplicons were

172 fused using a NEBuilder HiFi DNA Assembly kit (New England Biolabs, Ipswich, MA,

173 USA) according to the manufacturer's instructions. Then, to delete the GPI anchor-encoding

174 region of $a m y D$, PCR amplification was performed with primers ANamyD-dGPI-Fw and

175 ANamyD-dGPI-Rv from the resulting pAHT-amyD plasmid with PrimeSTAR Max DNA

176 Polymerase (Takara Bio Inc., Kusatsu, Japan). The amplified fragment was transformed into

177 DH5 $\alpha$ competent cells, and the pAHT-amyD( $\Delta \mathrm{GPI})$ plasmid was obtained (Fig. S3A). To

178 construct pAHdPT-amyD, the first half (amplicon 1) and the second half (amplicon 2) of

179 pyrG were amplified from A. oryzae genomic DNA. The fragment containing $h p h$, tefl

180 promoter, and amyD (amplicon 3) was amplified from pAHT-amyD. The three amplicons

181 were fused using a NEBuilder kit. For pAHdPT-amyD( $\Delta \mathrm{GPI})$ construction, the fragment

182 containing $h p h$, tefl promoter, and $a m y D$ lacking its GPI anchor-coding region (amplicon 3')

183 was amplified from pAHT-amyD( $\Delta$ GPI). The three amplicons and the SacI-digested pUC19

184 vector were fused using an In-Fusion HD Cloning Kit (Fig. S3B). The pAHdPT-amyD and

$185 \mathrm{pAHdPT}$-amyD( $\triangle \mathrm{GPI})$ plasmids were digested with $S a c \mathrm{I}$ and transformed into the $\triangle a m y D$

186 and $a g s B^{O E} \triangle a m y D$ strains (Fig. S3C). Correct integration of the cassettes was confirmed by

187 PCR (Fig. S3D).

\section{RNA extraction and quantitative real-time PCR}

189 Mycelial cells cultured in CD liquid medium for $24 \mathrm{~h}$ were collected, and total RNA was

190 extracted from the cells by using Sepasol-RNA I Super G (Nakalai Tesque, Kyoto, Japan) in

191 accordance with the manufacturer's instruction. The total RNA $(2.5 \mu \mathrm{g})$ was reverse-

192 transcribed by using a SuperScript IN VILO Master Mix with ezDNase Enzyme (Invitrogen,

193 Carlsbad, CA, United States). Quantitative real-time PCR was performed with a Mx3000P

194 (Agilent Technologies, Santa Clara, CA, United States) with SYBR Green detection. For

195 reaction mixture preparation, Thunderbird Next SYBR qPCR Mix (Toyobo Co., Ltd., Osaka,

196 Japan) was used. Primers used for quantitative PCR are listed in Table S1. An equivalent 
197 amount of cDNA, obtained from reverse transcription reactions using an equivalent amount of

198 total RNA, was applied to each reaction mixture. The gene encoding histone H2B was used as

199 a normalization reference (an internal control) for determining the target gene expression

200 ratios.

\section{Delipidization and fractionation of mycelial cells}

202 Cell walls were fractionated as previously described with some modification (Miyazawa et

203 al., 2018). Mycelia cultured for $24 \mathrm{~h}$ in CD medium were collected by filtering through

204 Miracloth (Merck Millipore, Darmstadt, Germany), washed with water, and freeze-dried. The

205 mycelia were then pulverized in a MM400 bench-top mixer mill (Retch, Haan, Germany).

206 The powder $(1 \mathrm{~g})$ was suspended in $25 \mathrm{~mL}$ of chloroform-methanol (3:1 vol/vol) and stirred

207 at room temperature for $12 \mathrm{~h}$ to remove the total polar lipid content of the mycelial cells. The

208 mixture was centrifuged $(10 \square 000 \times g, 10 \mathrm{~min})$. The residue was suspended in chloroform-

209 methanol, and the delipidizing procedure was repeated. Then the de-polar lipid residue was

210 suspended in $40 \mathrm{~mL}$ of $0.1 \mathrm{M}$ Na phosphate buffer ( $\mathrm{pH} 7.0$ ), and cell-wall components were

211 fractionated by hot-water and alkali treatments, as described previously (Miyazawa et al.,

212 2018). Hot-water-soluble, alkali-soluble, and alkali-insoluble fractions were obtained from

213 this fractionation, and the alkali-soluble fraction was further separated into a fraction soluble

214 in water at neutral $\mathrm{pH}$ (AS1) and an insoluble fraction (AS2). The monosaccharide

215 composition of AS2 fractions was quantified according to Miyazawa et al. (2018).

216 To obtain mycelia cultured for $16 \mathrm{~h}$, conidia (final conc. $5.0 \times 10^{5} / \mathrm{mL}$ ) were inoculated

217 into $200 \mathrm{~mL} \mathrm{CD}$ medium and rotated at $160 \mathrm{rpm}$ at $37^{\circ} \mathrm{C}$. The mycelia were collected and

218 fractionated as described above.

\section{$219{ }^{13}$ C NMR analysis}

220 The AS2 fraction of each strain (50 mg) was suspended in $1 \mathrm{~mL}$ of $1 \mathrm{M} \mathrm{NaOH} / \mathrm{D}_{2} \mathrm{O}$ and

221 dissolved by vortexing. One drop of DMSO- $\mathrm{d}_{6}$ (deuterated dimethyl sulfoxide) was then

222 added to each fraction and the solutions were centrifuged $(3,000 \times g, 5 \mathrm{~min})$ to remove

223 insoluble debris. ${ }^{13} \mathrm{C}$ NMR spectra of the supernatants were obtained using a JNM-ECX400P

224 spectrometer (JEOL, Tokyo, Japan) at $400 \mathrm{MHz}$ at $35^{\circ} \mathrm{C}$. Chemical shifts were recorded

225 relative to the resonance of DMSO- $\mathrm{d}_{6}$.

\section{Determination of the average molecular mass of alkali-soluble glucan}

227 The MM of alkali-soluble glucan was determined by gel permeation chromatography (GPC)

228 according to the methods of Puanglek et al. (2016), with some modification. A GPC-101 
system (Showa Denko Co. Ltd., Tokyo, Japan) with an ERC-3125S degasser (Showa Denko) and an RI-71S refractive index detector (Showa Denko) was used for the measurement. It was fitted with a GPC KD-G 4A guard column (Showa Denko) and a GPC KD-805 column $(8.0 \times$ $300 \mathrm{~mm}$; Showa Denko). The eluent was $20 \mathrm{mM} \mathrm{LiCl}$ in $N, N$-dimethylacetamide (DMAc), and the flow rate was $0.6 \mathrm{~mL} / \mathrm{min}$ at $40^{\circ} \mathrm{C}$. The detector was normalized with polystyrene standards (SM-105; Showa Denko). With SmartChrom software (Jasco, Tokyo, Japan), the GPC profile was divided into virtual time slices $\left(\mathrm{n}_{i}\right)$ with the height of each virtual slice from the base line $\left(H_{i}\right)$ corresponding to a certain $\mathrm{MM}\left(M_{i}\right)$ obtained by calibrating the column. From these values, the number-average $\mathrm{MM}\left(M_{\mathrm{n}}\right)$ and weight-average $\mathrm{MM}\left(M_{\mathrm{w}}\right)$ were calculated as:

$$
\begin{gathered}
M_{\mathrm{n}}=\sum H_{\mathrm{i}} / \sum\left(H_{\mathrm{i}} / M_{\mathrm{i}}\right) \\
M_{\mathrm{w}}=\sum\left(H_{\mathrm{i}} \cdot M_{\mathrm{i}}\right) / \sum H_{\mathrm{i}}
\end{gathered}
$$

Polydispersity was calculated as $M_{\mathrm{w}} / M_{\mathrm{n}}$.

\section{Smith degradation}

Smith degradation of the alkali-soluble glucan was performed as described (Miyazawa et al., 2018).

\section{Fluorescent labeling of cell-wall polysaccharides}

Mycelial cells cultured for $16 \mathrm{~h}$ in CD liquid medium were dropped on a glass slide and dried at $55^{\circ} \mathrm{C}$ for $15 \mathrm{~min}$. The cells were fixed, labeled with fluorophores, and imaged by confocal scanning microscopy as described (Miyazawa et al., 2018). Enzymatic digestion of $\beta-1,3-$ glucan in the hyphal cells was performed as described (Miyazawa et al., 2018).

\section{Results}

\section{Characterization of strains with disrupted or overexpressed amyD}

We constructed $a m y D^{O E}$ and $\triangle a m y D$ strains by introducing the $a m y D$ cassettes for overexpression and disruption into the wild-type, $a_{S S} A^{O E}$, and $\operatorname{ags}_{S}{ }^{O E}$ strains (Fig. S2). The expression level of $a m y D$ in each strain was quantified in hyphal cells. Whereas each disrupted strain $\left(\triangle a m y D, a g s A^{O E} \triangle a m y D\right.$, and $\left.a g s B^{O E} \triangle a m y D\right)$ showed scarce $a m y D$ expression, each overexpressing strain $\left(a m y D^{O E}, a g s A^{O E} a m y D^{O E}\right.$, and $a g s B^{O E} a m y D^{O E}$ ) showed significantly higher $a m y D$ expression than the parental strains (Fig. 1).

There was no significant difference in radial growth among the strains grown on agar plates for 5 days (Fig. S4). In liquid culture, the wild-type and $\triangle a m y D$ strains formed tightly 
260 aggregated hyphal pellets; however, the hyphae of the $a m y D^{O E}$ strain were almost fully

261 dispersed (Fig. 2). He et al. reported that the phenotype of their $a m y D^{O E}$ strain resembles that

262 of the $\triangle a g s B$ strain in A. nidulans (He et al., 2014), which is consistent with our results (Fig.

263 2). In agreement with our previous results (Miyazawa et al., 2018), the $\operatorname{ags}_{s}{ }^{O E}$ and $\operatorname{ags}_{S}{ }^{O E}$

264 strains formed, respectively, loosely and tightly aggregated pellets (Fig. 2). Disruption of

$265 a m y D$ did not affect the phenotypes of the $a g s A^{O E}$ and $a g s B^{O E}$ strains (Fig. 2). Also,

266 overexpression of $a m y D$ scarcely affected the phenotypes of the $a g s A^{O E}$ and $a g s B^{O E}$ strains

267 (Fig. 2).

268 Overexpression of $a m y D$ resulted in a decrease in cell-wall alkali-soluble glucan

269 Cell-wall components of each strain were fractionated by a hot water-alkali treatment

270 method, each fraction was weighed, and the monosaccharide composition of the AS2 fraction

271 was quantified. The amount of glucose in the AS2 fraction was significantly lower in the

$272 a m y D^{O E}$ strain than in the wild-type strain (Fig. 3A; $P<0.05$ ). That in the $\triangle a m y D$ strain was

273 similar to that in the wild-type strain (Fig. 3A). Those in the $a g s A^{O E} a m y D^{O E}$ and

$274 a g s A^{O E} \triangle a m y D$ strains, which were constructed from the parental strain ags $A^{O E}$, were almost

275 the same (Fig. 3B). It was significantly lower in the $\operatorname{agsB}^{O E}$ amy $D^{O E}$ strain than in the $\operatorname{ags}^{O E}$

276 and $a g s B^{O E} \triangle a m y D$ strains (Fig. 3C; $P<0.05$ ). These results indicate that AmyD acts to

277 decrease the amount of alkali-soluble glucan in the wild-type and $\operatorname{ags}^{O E}$ strains, but not in

278 the $\operatorname{ags}_{s}{ }^{O E}$ strain, even when $a m y D$ is overexpressed.

279 Overexpression of the $a m y D$ gene decreases the molecular mass of alkali-soluble glucan

280 By ${ }^{13} \mathrm{C}$ NMR analysis, the primary component in the AS2 fraction of the wild-type, amy $D^{O E}$,

281 and $\triangle a m y D$ strains was found to be $\alpha-1,3$-glucan, suggesting that amy $D$ did not affect the

282 primary components of alkali-soluble glucan (Fig. S5). To reveal whether the MM of alkali-

283 soluble glucan was affected by disruption or overexpression of $a m y D$, we determined the MM

284 of alkali-soluble glucan in each strain by GPC analysis. Polystyrene (MM, 13 $\square 900$

$2853 \square 850 \square 000$ ) was used as a standard molecule to calibrate the column for size exclusion

286 analysis. Although the physical properties of a polymer depend on $M_{\mathrm{w}}$, the number of moles is

287 important for a biological reaction. Here we focus on the MM of alkali-soluble glucan with

$288 M_{\mathrm{n}}$. The $M_{\mathrm{n}}$ of the alkali-soluble glucan was $1 \square 260 \square 000 \pm 270 \square 000$ in the $\operatorname{ags}^{O E}$ strain and

$289312 \square 000 \pm 3 \square 000$ in $a g s B^{O E}$ strain (Fig. 4A, B; Table 2), consistent with our previous results

290 (Miyazawa et al., 2018). Although the $M_{\mathrm{n}}$ of alkali-soluble glucan in the $a g s A^{O E} a m y D^{O E}$

291 strain $(1 \square 110 \square 000 \pm 60 \square 000)$ was similar to that in the parental $\left(\operatorname{ags} A^{O E}\right)$ strain, that of

$292 a g s A^{O E} \triangle a m y D$ was significantly greater $(2 \square 250 \square 000 \pm 130 \square 000)$ than that of ags $A^{O E}$ (Fig. 
293

294

295

296

297

298

299

300

301

302

303

304

305

306

307

308

309

310

311

312

313

314

315

316

317

318

319

320

321

322

323

324

325

4A; Table 2, $P<0.05)$. In addition, the $M_{\mathrm{n}}$ of $a g s B^{O E} a m y D^{O E}(140 \square 000 \pm 4 \square 000)$ was significantly less than that of the parental $\left(a g s B^{O E}\right)$ strain (Fig. 4B; Table $\left.2, P<0.05\right)$. The $M_{\mathrm{n}}$ of alkali-soluble glucan in $\operatorname{ags}_{S} B^{O E} \triangle a m y D(358 \square 000 \pm 11 \square 000)$ was similar to that in $a g s B^{O E}$ (Fig. 4B; Table 2). Lastly, the $M_{\mathrm{n}}$ of alkali-soluble glucan in the wild type (2 $\square 280 \square 000 \pm$ $130 \square 000)$ and $\triangle a m y D(2 \square 390 \square 000 \pm 390 \square 000)$ was larger than that in $a g s B^{O E}(312 \square 000 \pm$ $3 \square 000$; Fig. 4C; Table 2). The $a m y D^{O E}$ strain had a primary peak at around $17 \min \left(M_{\mathrm{n}}{ }^{1}\right.$, $32 \square 900 \pm 300)$ and a secondary peak at $11 \min \left(M_{\mathrm{n}}{ }^{2}, 2 \square 210 \square 000 \pm 700 \square 000\right)$. These results suggest that AmyD degraded the alkali-soluble glucan eluted around 11 min to produce alkali-soluble glucan with a smaller MM (Fig. 4C; Table 2).

We predicted that an unknown modification enzyme may increase the MM of alkalisoluble glucan in the endogenous ags $B$-expressing strain because the alkali-soluble glucan in these strains was synthesized mainly by AgsB. Therefore, we determined the MM of alkalisoluble glucan extracted from 16-h cultured mycelia, which should be less affected by the modification enzyme than the 24-h cultured mycelia (He et al., 2017). Unexpectedly, the $M_{\mathrm{n}}$ of the alkali-soluble glucan in the mycelia cultured for $16 \mathrm{~h}$ was $1 \square 980 \square 000 \pm 320 \square 000$, which was similar to that in the mycelia cultured for $24 \mathrm{~h}(1 \square 930 \square 000 \pm 280 \square 000$; Fig. S6; Table S2). We then evaluated the MM of alkali-soluble glucan in A4, which had $M_{\mathrm{n}}=$ $2 \square 224 \square 000 \pm 390 \square 000$, similar to that in the wild-type strain (Table S3).

To validate whether the degree of polymerization of $\alpha$-1,3-glucan subunits in the alkalisoluble glucan was altered when the MM was changed by amy $D$ disruption or overexpression, we applied Smith degradation to the alkali-soluble glucan from each strain to selectively cleave 1,4-linked glucan, and then determined the MM by GPC. One subunit of $\alpha-1,3$-glucan in the alkali-soluble glucan is composed of $\approx 200$ glucose residues (Choma et al., 2013; Miyazawa et al., 2018). The Smith-degraded alkali-soluble glucan in each strain had almost the same MM, equivalent to 300-400 glucose residues (Fig. S7; Table S4), which suggests that AmyD activity does not decrease the degree of polymerization of the glucose residues in each $\alpha-1,3$-glucan subunit.

\section{Spatial localization of $\alpha-1,3$-glucan in the cell wall is not affected by amyD disruption or} overexpression

We previously revealed that spatial localization of $\alpha-1,3$-glucan in the cell wall changes according to its MM (Miyazawa et al., 2018); $\alpha$-1,3-glucans in $\operatorname{ags}_{S} B^{O E}$ cells are localized in the outer layer in the cell wall, whereas most of those in the $\operatorname{ags} A^{O E}$ cells are masked by a $\beta$ 1,3-glucan layer. In this study, disruption or overexpression of amyD altered the MM of 
326 alkali-soluble glucan (Fig. 4; Table 2); therefore, we analyzed whether this alteration affected

327 the spatial localization of $\alpha-1,3$-glucan in the cell wall. In agreement with previous results

328 (Miyazawa et al., 2018), the $\alpha$-1,3-glucans with AGBD-GFP labeling showed clearly in the

329 wild-type and $a g s B^{O E}$ cells, but only weakly in $a g s A^{O E}$ cells (Fig. 5). The $\triangle a m y D$ and $a m y D^{O E}$

330 cells were also labeled with AGBD-GFP (Fig. 5); fluorescent intensity in $a m y D^{O E}$ was

331 relatively low, which might be caused by a decrease in the amount of alkali-soluble glucan in

332 the cell wall of $a m y D^{O E}$ cells. The labeling with AGBD-GFP in $a g s A^{O E} a m y D^{O E}$ and

$333 \operatorname{agsA}^{O E} \triangle a m y D$ cells was weak, as was that in the cells of the parental $\operatorname{ags}_{S}{ }^{O E}$ strain (Fig. 5).

334 The $a_{s} B^{O E} \triangle a m y D$ cells were clearly labeled with AGBD-GFP, as in the parental ags $B^{O E}$

335 (Fig. 5). The AGBD-GFP labeling was slightly weaker in $a g s B^{O E} a m y D^{O E}$ than in $a g s B^{O E}$,

336 which might be attributable to a decrease in the amount of $\alpha-1,3$-glucan. After treatment with

$337 \beta$-1,3-glucanase, $\alpha$-1,3-glucans of the hyphal cells in $a g s A^{O E}, a g s A^{O E} a m y D^{O E}$, and

$338 \operatorname{agsA}^{O E} \triangle a m y D$ cells were clearly labeled with AGBD-GFP (Fig. S8), suggesting that these

339 strains have $\alpha-1,3$-glucan in the inner layer of the cell wall in their hyphal cells. Taken

340 together, these findings indicate that disruption or overexpression of $a m y D$ gene scarcely

341 affected the spatial localization of $\alpha-1,3$-glucan in the cell wall.

342 The GPI anchor is essential for the effect of AmyD on both the amount and molecular

343 mass of alkali-soluble glucan

344 AmyD is thought to contain a GPI anchor at the C-terminal region. Fungal GPI anchor-type

345 proteins are transferred from the plasma membrane to the cell wall by the activity of the

346 GH76 family (Vogt et al., 2020). We speculated that localization in the cell wall would be

347 essential for AmyD to reach the substrate, alkali-soluble glucan, so we constructed

348 overexpression strains of $a m y D$ with and without the GPI-anchor site. Because we noticed

349 that overexpression of $a m y D$ alters the phenotype or the alkali-soluble glucan, we used

$350 \triangle a m y D$ and $a g s B^{O E} \triangle a m y D$ strains as hosts for the $a m y D^{O E}$ strains. The hyphae of $\triangle a m y D$

351 formed pellets in shake-flask culture (Fig. 6). Those of $\triangle a m y D$ - $a m y D^{O E}$ were dispersed, as in

$352 a m y D^{O E}$ (Fig. 6). Those of $\triangle a m y D$ - $a m y D^{O E}(\triangle \mathrm{GPI})$ formed pellets, although the form was

353 slightly different from that in the parental strain (Fig. 6). Those of $a g s B^{O E} \triangle a m y D$,

$354 a g s B^{O E} \triangle a m y D$ - $a m y D^{O E}$, and $a g s B^{O E} \triangle a m y D$ - $a m y D^{O E}(\triangle \mathrm{GPI})$ formed similar pellets (Fig. 6).

355 Although the $\triangle a m y D$ - $a m y D^{O E}$ hyphae had less AS2-Glc $(1.13 \% \pm 0.21 \%)$ than $\triangle a m y D$

$356(5.68 \% \pm 0.25 \%)$, the amount was restored in $\triangle a m y D-a m y D^{O E}(\Delta \mathrm{GPI})$ hyphae $(5.17 \% \pm$

$3570.46 \%$; Fig. 7A). These results suggest that the GPI anchor of AmyD has an important

358 negative effect on $\alpha-1,3$-glucan biosynthesis. The hyphae of $a_{s} B^{O E} \triangle a m y D$-amy $D^{O E}$ had 
359

360

361

362

363

364

365

366

367

368

369

370

371

372

373

374

375

376

377

378

379

380

381

382

383

384

385

386

387

388

389

390

391

marginally less AS2-Glc $(16.2 \% \pm 0.6 \%)$ than those of $\operatorname{agsB}^{O E} \triangle a m y D(17.6 \% \pm 0.3 \%)$ and $\operatorname{agsB}^{O E} \triangle a m y D-a m y D^{O E}(\triangle \mathrm{GPI})(16.7 \% \pm 0.5 \%$; Fig. 7B). We then evaluated the MM of alkali-soluble glucan in the cells of $a g s B^{O E} \triangle a m y D, a g s B^{O E} \triangle a m y D$-amy $D^{O E}$, and $\operatorname{ags}^{O E} \triangle a m y D-a m y D^{O E}(\triangle \mathrm{GPI})$. The $M_{\mathrm{n}}$ of the alkali-soluble glucan in $a g s B^{O E} \triangle a m y D-$ $a m y D^{O E}$ cells $(174 \square 000 \pm 8 \square 000)$ was smaller than that in $a g s B^{O E} \triangle a m y D(270 \square 000 \pm$ $8 \square 000$; Fig. 7C; Table 3; $P<0.05)$. The $M_{\mathrm{n}}$ of alkali-soluble glucan in $a g s B^{O E} \triangle a m y D$ $a m y D^{O E}(\Delta \mathrm{GPI})$ cells (349 $\left.\square 000 \pm 42 \square 000\right)$ was similar to that in $a_{s} B^{O E} \Delta a m y D$ (Fig. 7C; Table 3). These results suggest that the GPI anchor of AmyD is also important for regulating the MM of alkali-soluble glucan.

\section{Discussion}

Although the GPI-anchored $\alpha$-amylase AmyD is known to be involved in the biosynthesis of $\alpha$-1,3-glucan in A. nidulans (He et al., 2014;He et al., 2017), the detailed mechanism remains unclear. Here, we looked at strains with disrupted or overexpressed $a m y D$ to analyze how AmyD affects the chemical properties of alkali-soluble glucan. The results reveal that overexpression of amyD not only decreased the MM of $\alpha-1,3$-glucan, but also decreased the amount of $\alpha-1,3$-glucan in the cell wall. The GPI anchor of AmyD was essential in both actions.

Overexpression of $a m y D$ affected the amount and $M M$ of $\alpha-1,3$-glucan in the wild-type and $\operatorname{ags} B^{O E}$ strains, but not in the $\operatorname{ags} A^{O E}$ strain (Fig. 3; Fig. 4; Table 2). We previously reported that the MM of $\alpha-1,3$-glucan controls where $\alpha$-1,3-glucan is localized in the cell wall of $A$. nidulans; namely, that the $\alpha-1,3$-glucan with a larger MM that is synthesized by AgsA is localized in the inner layer of the cell wall, and the smaller one that is synthesized by AgsB is localized in the outer layer (Miyazawa et al., 2018). This phenomenon is explained by the fact that fungal GPI-anchored proteins are transferred from the plasma membrane to the cell wall (Orlean, 2012; Gow et al., 2017). The findings here suggest that AmyD decreased the MM of $\alpha-1,3$-glucan localized at the outer layer of the cell wall. The increased MM of alkali-soluble glucan in the $\operatorname{ags}^{O E} \triangle a m y D$ strain can be explained by its GPC elution profiles which suggest that the MM of the polysaccharides was broadly distributed (Fig. 4A); in other words, $\operatorname{ags} A^{O E} \triangle a m y D$ had mainly $\alpha$-1,3-glucan with larger MM $\left(>623 \square 000\left[M_{\mathrm{p}}\right.\right.$ of alkali-soluble glucan from $\left.\operatorname{ags}^{O E}\right], 97.5 \%$ ), but also had a small amount of $\alpha$-1,3-glucan with small MM $(<623 \square 000,2.5 \%)$. We speculate that this small amount of $\alpha-1,3$-glucan with a smaller MM may be localized in the outer layer of the cell wall of $\operatorname{ags} A^{O E}$, where it is accessible to AmyD, which results in the relatively smaller MM of $\alpha$-1,3-glucan. Immunoelectron microscopic 
392 analysis would be able to reveal the relationship between the spatial localization of AmyD

393 and $\alpha-1,3$-glucan in the cell wall.

394 AmyD of $A$. nidulans is considered to be a GPI-anchored protein (de Groot et al.,

395 2009; He et al., 2014). It is well known that many fungal GPI-anchored proteins are related to

396 remodeling of the cell wall (Samalova et al., 2020). Proteins in the "defective in filamentous

397 growth" (DFG) family recognize the GPI core glycan and then transfer to the $\beta-1,3-$ or $\beta-1,6-$

398 glucan (Muszkieta et al., 2019; Vogt et al., 2020), which allows GPI-anchored proteins to react

399 with their substrates in the cell wall. Although there is no direct evidence that DFG family

400 proteins contribute to transglycosylation in Aspergillus species, their role in cell-wall integrity

401 in A. fumigatus was recently reported (Li et al., 2018;Muszkieta et al., 2019), which implies

402 that DFG family proteins are important for transferring the GPI-core glycan to $\beta$-glucan in

403 Aspergillus species. To reveal the importance of the GPI anchor in the function of AmyD, we

404 evaluated the MM and amount of $\alpha-1,3$-glucan in amyD-overexpressing strains with or

405 without the GPI-anchoring site. Interestingly, decreases in the MM and the amount of $\alpha-1,3-$

406 glucan were not observed when the C-terminal GPI-anchoring site was deleted (Fig. 7; Table

407 3); $\triangle a m y D-a m y D^{O E}(\Delta \mathrm{GPI})$ formed slightly altered pellets (Fig. 6), suggesting that AmyD

408 expressed without its GPI anchor has only partial functions. Above all, the results show that

409 expression of AmyD with a GPI anchor is important for reaching the substrate, $\alpha$-1,3-glucan,

410 in the space of the cell wall.

411 Cell-wall polysaccharides are thought to be synthesized on the plasma membrane after

412 the secretory vesicles containing polysaccharide synthases have been exported to the hyphal

413 tip (Riquelme, 2013). On the basis of our previous findings (Miyazawa et al., 2020), we

414 hypothesize the process of alkali-soluble glucan biosynthesis of A. nidulans to be as follows:

415 (1) the intracellular domain of $\alpha$-1,3-glucan synthase polymerizes 1,3-linked $\alpha$-glucan chains

416 from UDP-glucose as a substrate from the primers, which are maltooligosaccharides produced

417 by intracellular $\alpha$-amylase AmyG; (2) the elongated glucan chain is exported to the

418 extracellular space through the multitransmembrane domain of $\alpha$-1,3-glucan synthase; (3) the

419 extracellular domain of $\alpha-1,3$-glucan connects several chains of the elongated glucan to form

420 mature alkali-soluble glucan. The mechanism underlying the distribution of mature alkali-

421 soluble glucan to the cell-wall network is still unknown. However, the water solubility of

422 newly synthesized glucan might be related to the spatial distribution of $\alpha-1,3$-glucan in the

423 cell wall, because localization of $\alpha$-1,3-glucan varies according to the difference in MM

424 (Miyazawa et al., 2018). Aspergillus niger AgtA (encoded by an orthologue of A. nidulans

425 amy $D$ ) scarcely hydrolyzes $\alpha$-1,3-glucan and shows weak hydrolytic activity to starch (van 
426 der Kaaij et al., 2007). Therefore, decrease of the MM of alkali-soluble glucan in the $a m y D^{O E}$

427 strain could be caused by hydrolysis of the primer/spacer residues (1,4-linked $\alpha$-glucan) rather

428 than of the 1,3-linked $\alpha$-glucan region. The mechanism underlying the decrease in the amount

429 of $\alpha-1,3$-glucan by AmyD is also unknown. He et al. reported that AmyD seems to directly

430 repress $\alpha$-1,3-glucan synthesis (He et al., 2017). We suspect that AmyD with a GPI anchor on

431 the plasma membrane binds to the spacer residues of a glucan chain that is being just

432 synthesized by $\alpha-1,3$-glucan synthase, and competitively inhibits transglycosylation by the

433 extracellular domain of $\alpha$-1,3-glucan synthase to decrease the amount of alkali-soluble glucan

434 in the cell wall.

435 The $M_{\mathrm{n}}$ of the alkali-soluble glucan from the wild-type strain was larger than that from

436 the $a g s B^{O E}$, although the alkali-soluble glucan from both strains seemed to be synthesized

437 mainly by AgsB (Fig. 4; Table 2). The $M_{\mathrm{n}}$ of the alkali-soluble glucan in the 16-h-cultured

438 mycelia from the wild-type was similar to that from the 24-h-cultured mycelia (Fig. S6; Table

439 S2). $\alpha-1,3-$ Glucan was clearly labeled with AGBD-GFP in the wild-type strain (Fig. 5). These

440 results suggest that $\alpha$-1,3-glucan was located in the outer layer of the cell wall in the wild-type

441 strain, consistent with the localization of $\alpha-1,3$-glucan synthesized by AgsB. These results

442 imply the existence of some factor that increases the MM of $\alpha$-1,3-glucan. We surmise that

443 once a matured $\alpha-1,3$-glucan molecule synthesized by AgsB is localized in the outer layer of

444 the cell wall, macromolecules are formed by interconnecting $\alpha$-1,3-glucan or connecting $\alpha$ -

445 1,3-glucan to other polysaccharides, resulting in a chemically stable complex. Although the

446 difference was not significant, the MM of Smith-degraded alkali-soluble glucan in the wild-

447 type strain was slightly higher (Table S4) and its GPC profile had a broader distribution (Fig.

$448 \mathrm{~S} 7)$ than those in the $a g s A^{O E}$ and $a g s B^{O E}$ strains, implying the existence of non-Smith-

449 degradable glycosidic bonds (i.e. $\beta$-1,3-glycosidic bond) in the alkali-soluble fraction in the

450 wild-type strain. It is well known that $\beta$-glucan, chitin, and galactomannan are continuously

451 modified by hydrolase or glycosyltransferase in the cell wall (Aimanianda et al., 2017;Henry

452 et al., 2019; Muszkieta et al., 2019). However, an enzyme that modifies $\alpha$-1,3-glucan has not

453 been reported. Recently the GPI-anchored glycosyltransferase Crh, which has a role in the

454 crosslinking reaction for both glucan-glucan and glucan-chitin, has been reported (Fang et

455 al., 2019). A similar enzyme that has a role in modifying $\alpha$-1,3-glucan might be found soon.

456 Here, we revealed that AmyD in A. nidulans decreased the MM of the alkali-soluble

457 glucan composed mainly of $\alpha-1,3$-glucan in the cell wall and the amount of alkali-soluble

458 glucan. However, a complete picture of the biosynthesis of $\alpha-1,3$-glucan has yet to be

459 described, because the substrates or proteins associated with $\alpha$-1,3-glucan synthesis have not 
460 been directly demonstrated. To unveil the true nature of the biosynthesis, further biochemical

461 analysis of the $\alpha-1,3$-glucan synthase is essential.

\section{Conflict of interest}

463 The authors declare that the research was conducted in the absence of any commercial or

464 financial relationships that could be construed as a potential conflict of interest.

\section{Author contributions}

$466 \mathrm{KM}, \mathrm{AY}, \mathrm{TN}$, and KA conceived and designed the experiment. KM, TY, and AT performed

467 most experiments and analyzed the data. KM, YK, and YT performed microscopic

468 observation. KM, AY, MS, and YY constructed fungal mutants. SK performed ${ }^{13} \mathrm{C}$ NMR. AK

469 and SY produced AGBD-GFP. KM, AY, and KA wrote the paper. KA supervised this

470 research and acquired funding.

\section{$471 \quad$ Funding}

472 This work was supported by the Japan Society for Promotion of Science (JSPS) KAKENHI

473 Grant numbers 26292037 (KA), 18K05384 (KA), and 20K22773 (KM), and a Grant-in-Aid

474 for JSPS Fellows Grant Number 18J11870 (KM). This work was also supported by the

475 Institute for Fermentation, Osaka (Grant No. L-2018-2-014) (KA) and by the project

476 JPNP20011 (KA), which is commissioned by the New Energy and Industrial Technology

477 Development Organization (NEDO).

\section{Acknowledgment}

479 We are grateful to Associate Professor Toshikazu Komoda (Miyagi University) for the NMR.

\section{References}

481

482

483

484

485

486

487

488

489

490

491
Aimanianda, V., Simenel, C., Garnaud, C., Clavaud, C., Tada, R., Barbin, L., Mouyna, I., Heddergott, C., Popolo, L., Ohya, Y., Delepierre, M., and Latge, J.P. (2017). The dual activity responsible for the elongation and branching of $\beta-(1,3)$-glucan in the fungal cell wall. mBio 8.

Beauvais, A., Bozza, S., Kniemeyer, O., Formosa, C., Balloy, V., Henry, C., Roberson, R.W., Dague, E., Chignard, M., Brakhage, A.A., Romani, L., and Latgè, J.P. (2013). Deletion of the $\alpha$-(1,3)-glucan synthase genes induces a restructuring of the conidial cell wall responsible for the avirulence of Aspergillus fumigatus. PLoS Pathog. 9, e1003716.

Beauvais, A., Maubon, D., Park, S., Morelle, W., Tanguy, M., Huerre, M., Perlin, D.S., and Latge, J.P. (2005). Two $\alpha(1-3)$ glucan synthases with different functions in Aspergillus fumigatus. Appl. Environ. Microbiol. 71, 1531-1538. 
492

493

494

495

496

497

498

499

500

501

502

503

504

505

506

507

508

509

510

511

512

513

514

515

516

517

518

519

520

521

522

523

524

525

526

527

528

529

530

531

532

533

534

535

536

537

538

539

540

541

Bernard, M., and Latge, J.P. (2001). Aspergillus fumigatus cell wall: composition and biosynthesis. Med. Mycol. 39 Suppl 1, 9-17.

Choma, A., Wiater, A., Komaniecka, I., Paduch, R., Pleszczynska, M., and Szczodrak, J. (2013). Chemical characterization of a water insoluble (1-->3)- $\alpha$-D-glucan from an alkaline extract of Aspergillus wentii. Carbohydr. Polym. 91, 603-608.

Damveld, R.A., Vankuyk, P.A., Arentshorst, M., Klis, F.M., Van Den Hondel, C.A., and Ram, A.F. (2005). Expression of agsA, one of five 1,3- $\alpha$-D-glucan synthase-encoding genes in Aspergillus niger, is induced in response to cell wall stress. Fungal Genet. Biol. 42, 165-177.

De Groot, P.W.J., Brandt, B.W., Horiuchi, H., Ram, A.F.J., De Koster, C.G., and Klis, F.M. (2009). Comprehensive genomic analysis of cell wall genes in Aspergillus nidulans. Fungal Genetics and Biology 46, S72-S81.

Dichtl, K., Samantaray, S., Aimanianda, V., Zhu, Z., Prevost, M.C., Latgè, J.P., Ebel, F., and Wagener, J. (2015). Aspergillus fumigatus devoid of cell wall $\beta-1,3$-glucan is viable, massively sheds galactomannan and is killed by septum formation inhibitors. Mol. Microbiol. 95, 458-471.

Fang, W., Sanz, A.B., Bartual, S.G., Wang, B., Ferenbach, A.T., Farkas, V., Hurtado-Guerrero, R., Arroyo, J., and Van Aalten, D.M.F. (2019). Mechanisms of redundancy and specificity of the Aspergillus fumigatus Crh transglycosylases. Nat. Commun. 10, 1669.

Fontaine, T., Beauvais, A., Loussert, C., Thevenard, B., Fulgsang, C.C., Ohno, N., Clavaud, C., Prevost, M.C., and Latgè, J.P. (2010). Cell wall $\alpha 1-3$ glucans induce the aggregation of germinating conidia of Aspergillus fumigatus. Fungal Genet. Biol. 47, 707-712.

Fontaine, T., Simenel, C., Dubreucq, G., Adam, O., Delepierre, M., Lemoine, J., Vorgias, C.E., Diaquin, M., and Latgè, J.P. (2000). Molecular organization of the alkali-insoluble fraction of Aspergillus fumigatus cell wall. J. Biol. Chem. 275, 27594-27607.

Fujikawa, T., Kuga, Y., Yano, S., Yoshimi, A., Tachiki, T., Abe, K., and Nishimura, M. (2009). Dynamics of cell wall components of Magnaporthe grisea during infectious structure development. Mol. Microbiol. 73, 553-570.

Fujikawa, T., Sakaguchi, A., Nishizawa, Y., Kouzai, Y., Minami, E., Yano, S., Koga, H., Meshi, T., and Nishimura, M. (2012). Surface $\alpha$-1,3-glucan facilitates fungal stealth infection by interfering with innate immunity in plants. PLoS Pathog. 8, e1002882.

Fujioka, T., Mizutani, O., Furukawa, K., Sato, N., Yoshimi, A., Yamagata, Y., Nakajima, T., and Abe, K. (2007). MpkA-dependent and -independent cell wall integrity signaling in Aspergillus nidulans. Eukaryot. Cell 6, 1497-1510.

Gow, N.a.R., Latge, J.P., and Munro, C.A. (2017). The fungal cell wall: structure, biosynthesis, and function. Microbiol. Spectr. 5, FUNK-0035-2016.

Grün, C.H., Hochstenbach, F., Humbel, B.M., Verkleij, A.J., Sietsma, J.H., Klis, F.M., Kamerling, J.P., and Vliegenthart, J.F. (2005). The structure of cell wall $\alpha$-glucan from fission yeast. Glycobiology 15, 245-257.

Hagiwara, D., Asano, Y., Marui, J., Furukawa, K., Kanamaru, K., Kato, M., Abe, K., Kobayashi, T., Yamashino, T., and Mizuno, T. (2007). The SskA and SrrA response regulators are implicated in oxidative stress responses of hyphae and asexual spores in the phosphorelay signaling network of Aspergillus nidulans. Biosci. Biotechnol. Biochem. 71, 1003-1014.

He, X., Li, S., and Kaminskyj, S. (2017). An amylase-like protein, AmyD, is the major negative regulator for $\alpha$-glucan synthesis in Aspergillus nidulans during the asexual life cycle. Int'l. J. Mol. Sci. 18, 695.

He, X.X., Li, S.N., and Kaminskyj, S.G.W. (2014). Characterization of Aspergillus nidulans $\alpha$-glucan synthesis: roles for two synthases and two amylases. Mol. Microbiol. 91, 
579-595.

Henry, C., Latgè, J.P., and Beauvais, A. (2012). 11,3 Glucans are dispensable in Aspergillus fumigatus. Eukaryot. Cell 11, 26-29.

Henry, C., Li, J., Danion, F., Alcazar-Fuoli, L., Mellado, E., Beau, R., Jouvion, G., Latgè, J.P., and Fontaine, T. (2019). Two KTR mannosyltransferases are responsible for the biosynthesis of cell wall mannans and control polarized growth in Aspergillus fumigatus. mBio 10, e02647-02618.

Krappmann, S., Sasse, C., and Braus, G.H. (2006). Gene targeting in Aspergillus fumigatus by homologous recombination is facilitated in a nonhomologous end- joining-deficient genetic background. Eukaryot. Cell 5, 212-215.

Latgè, J.P. (2010). Tasting the fungal cell wall. Cell. Microbiol. 12, 863-872.

Latgè, J.P., and Beauvais, A. (2014). Functional duality of the cell wall. Curr. Opin. Microbiol. 20, 111-117.

Latgè, J.P., Beauvais, A., and Chamilos, G. (2017). The cell wall of the human fungal pathogen Aspergillus fumigatus: biosynthesis, organization, immune response, and virulence. Annu. Rev. Microbiol. 71, 99-116.

Li, J., Mouyna, I., Henry, C., Moyrand, F., Malosse, C., Chamot-Rooke, J., Janbon, G., Latgé, J.-P., and Fontaine, T. (2018). Glycosylphosphatidylinositol anchors from galactomannan and GPI-anchored protein are synthesized by distinct pathways in Aspergillus fumigatus. J. Fungi 4, 19.

Maubon, D., Park, S., Tanguy, M., Huerre, M., Schmitt, C., Prevost, M.C., Perlin, D.S., Latgè, J.P., and Beauvais, A. (2006). AGS3, an $\alpha(1-3)$ glucan synthase gene family member of Aspergillus fumigatus, modulates mycelium growth in the lung of experimentally infected mice. Fungal Genet. Biol. 43, 366-375.

Miyazawa, K., Yoshimi, A., and Abe, K. (2020). The mechanisms of hyphal pellet formation mediated by polysaccharides, $\alpha$-1,3-glucan and galactosaminogalactan, in Aspergillus species. Fungal Biol. Biotechnol. 7, 10.

Miyazawa, K., Yoshimi, A., Kasahara, S., Sugahara, A., Koizumi, A., Yano, S., Kimura, S., Iwata, T., Sano, M., and Abe, K. (2018). Molecular mass and localization of $\alpha-1,3-$ glucan in cell wall control the degree of hyphal aggregation in liquid culture of Aspergillus nidulans. Front. Microbiol. 9, 2623.

Miyazawa, K., Yoshimi, A., Sano, M., Tabata, F., Sugahara, A., Kasahara, S., Koizumi, A., Yano, S., Nakajima, T., and Abe, K. (2019). Both galactosaminogalactan and $\alpha-1,3-$ glucan contribute to aggregation of Aspergillus oryzae hyphae in liquid culture. Front. Microbiol. 10, 2090.

Miyazawa, K., Yoshimi, A., Zhang, S., Sano, M., Nakayama, M., Gomi, K., and Abe, K. (2016). Increased enzyme production under liquid culture conditions in the industrial fungus Aspergillus oryzae by disruption of the genes encoding cell wall $\alpha$-1,3-glucan synthase. Biosci. Biotechnol. Biochem. 80, 1853-1863.

Muszkieta, L., Fontaine, T., Beau, R., Mouyna, I., Vogt, M.S., Trow, J., Cormack, B.P., Essen, L.-O., Jouvion, G., and Latgé, J.-P. (2019). The glycosylphosphatidylinositol-anchored $D F G$ family is essential for the insertion of galactomannan into the $\beta$ - $(1,3)$-glucanchitin core of the cell wall of Aspergillus fumigatus. mSphere 4.

Orlean, P. (2012). Architecture and biosynthesis of the Saccharomyces cerevisiae cell wall. Genetics 192, 775-818.

Puanglek, S., Kimura, S., Enomoto-Rogers, Y., Kabe, T., Yoshida, M., Wada, M., and Iwata, T. (2016). In vitro synthesis of linear $\alpha$-1,3-glucan and chemical modification to ester derivatives exhibiting outstanding thermal properties. Sci. Rep. 6, 30479.

Rappleye, C.A., Eissenberg, L.G., and Goldman, W.E. (2007). Histoplasma capsulatum $\alpha-$ $(1,3)$-glucan blocks innate immune recognition by the $\beta$-glucan receptor. Proc. Natl. 
601

602

603

604

605

606

607

608

609

610

611

612

613

614

615

616

617

618

619

620

621

622

623

624

625

626

627

628

629

630

631

632

633

634

635

636

637

Acad. Sci. U. S. A. 104, 1366-1370.

Rappleye, C.A., Engle, J.T., and Goldman, W.E. (2004). RNA interference in Histoplasma capsulatum demonstrates a role for $\alpha-(1,3)$-glucan in virulence. Mol. Microbiol. 53, 153-165.

Riquelme, M. (2013). Tip growth in filamentous fungi: A road trip to the apex. Annu. Rev. Microbiol. 67, 587-609.

Samalova, M., Carr, P., Bromley, M., Blatzer, M., Moya-Nilges, M., Latgé, J.P., and Mouyna, I. (2020). GPI anchored proteins in Aspergillus fumigatus and cell wall morphogenesis. Curr. Top. Microbiol. Immunol. 425, 167-186.

Sheppard, D.C., and Howell, P.L. (2016). Biofilm exopolysaccharides of pathogenic fungi: lessons from bacteria. J. Biol. Chem. 291, 12529-12537.

Stephen-Victor, E., Karnam, A., Fontaine, T., Beauvais, A., Das, M., Hegde, P., Prakhar, P., Holla, S., Balaji, K.N., Kaveri, S.V., Latge, J.P., Aimanianda, V., and Bayry, J. (2017). Aspergillus fumigatus cell wall $\alpha-(1,3)$-glucan stimulates regulatory T-cell polarization by inducing PD-L1 expression on human dendritic cells. J. Infect. Dis. 216, 12811294.

Tokashiki, J., Hayashi, R., Yano, S., Watanabe, T., Yamada, O., Toyama, H., and Mizutani, O. (2019). Influence of $\alpha-1,3$-glucan synthase gene agsE on protoplast formation for transformation of Aspergillus luchuensis. J. Biosci. Bioeng. 128, 129-134.

Uechi, K., Yaguchi, H., Tokashiki, J., Taira, T., and Mizutani, O. (2021). Identification of genes involved in the synthesis of fungal cell wall component nigeran and regulation of its polymerization in Aspergillus luchuensis. Appl. Environ. Microbiol., AEM0114421.

Van Der Kaaij, R.M., Yuan, X.L., Franken, A., Ram, A.F., Punt, P.J., Van Der Maarel, M.J., and Dijkhuizen, L. (2007). Two novel, putatively cell wall-associated and glycosylphosphatidylinositol-anchored $\alpha$-glucanotransferase enzymes of Aspergillus niger. Eukaryot. Cell 6, 1178-1188.

Vogt, M.S., Schmitz, G.F., Varón Silva, D., Mösch, H.U., and Essen, L.O. (2020). Structural base for the transfer of GPI-anchored glycoproteins into fungal cell walls. Proc. Natl. Acad. Sci. U. S. A. 117, 22061-22067.

Yoshimi, A., Miyazawa, K., and Abe, K. (2016). Cell wall structure and biogenesis in Aspergillus species. Biosci. Biotechnol. Biochem. 80, 1700-1711.

Yoshimi, A., Miyazawa, K., and Abe, K. (2017). Function and biosynthesis of cell wall $\alpha-1,3-$ glucan in fungi. J. Fungi 3, 63.

Yoshimi, A., Sano, M., Inaba, A., Kokubun, Y., Fujioka, T., Mizutani, O., Hagiwara, D., Fujikawa, T., Nishimura, M., Yano, S., Kasahara, S., Shimizu, K., Yamaguchi, M., Kawakami, K., and Abe, K. (2013). Functional analysis of the $\alpha$-1,3-glucan synthase genes ags $A$ and ags $B$ in Aspergillus nidulans: AgsB is the major $\alpha-1,3$-glucan synthase in this fungus. PLoS One 8, e54893.

Zhang, S., Ban, A., Ebara, N., Mizutani, O., Tanaka, M., Shintani, T., and Gomi, K. (2017a). Self-excising Cre/mutant lox marker recycling system for multiple gene integrations and consecutive gene deletions in Aspergillus oryzae. J. Biosci. Bioeng. 123, 403-411.

Zhang, S., Sato, H., Ichinose, S., Tanaka, M., Miyazawa, K., Yoshimi, A., Abe, K., Shintani, T., and Gomi, K. (2017b). Cell wall $\alpha$-1,3-glucan prevents $\alpha$-amylase adsorption onto fungal cell in submerged culture of Aspergillus oryzae. J. Biosci. Bioeng. 124, 47-53. 
638 Table 1. Strains used in this study.

\begin{tabular}{|c|c|c|}
\hline Strains & Genotype & References \\
\hline$\overline{\mathrm{A} 4}$ & & FGSC $^{\mathrm{a}}$ \\
\hline $\begin{array}{l}\text { ABPU1 }\left(\arg B^{+}\right) \\
\text {(wild-type) }\end{array}$ & biA1, pyrG89, wA3, argB2, pyroA4, veA1, ligD::ptrA, AoargB $B^{+}$ & $\begin{array}{l}\text { (Hagiwara et al., } \\
\text { 2007; Miyazawa et al. } \\
\text { 2018) }\end{array}$ \\
\hline$\triangle a m y D$ & biA1, pyrG89, wA3, argB2, pyroA4, veA1, ligD::ptrA, Aoarg $B^{+}$, amyD::pyrxG & This study \\
\hline$a m y D^{O E}$ & $\begin{array}{l}\text { biA1, pyrG89, wA3, argB2, pyroA4, veA1, ligD::ptrA, AoargB }{ }^{+}, \text {Ptef1- } \\
\text { amyD::pyrG }\end{array}$ & This study \\
\hline$\triangle a g s A$ & biA1, pyrG89, wA3, argB2, pyroA4, veA1, $\operatorname{lig} D:: p \operatorname{tr} A, \operatorname{Aoarg} B^{+}, \operatorname{ags} A:: \operatorname{lox} P$ & This study \\
\hline $\operatorname{ags} B^{O E}$ & $\begin{array}{l}\text { biA1, pyrG89, wA3, argB2, pyroA4, veA1, ligD::ptrA, Aoarg } B^{+}, \text {ags } A:: \operatorname{lox} P . \\
\text { Ptef1-agsB::pyroA }\end{array}$ & This study \\
\hline $\operatorname{ags}_{s}{ }^{O E} \triangle a m y D$ & $\begin{array}{l}\text { biA1, pyrG89, wA3, argB2, pyroA4, veA1, ligD::ptrA, AoargB }{ }^{+}, \text {agsA::loxP, } \\
\text { Ptef1-agsB::pyroA, amyD::pyrG }\end{array}$ & This study \\
\hline $\operatorname{ags} B^{O E} a m y D^{O E}$ & $\begin{array}{l}\text { biA1, pyrG89, wA3, argB2, pyroA4, veA1, ligD::ptrA, AoargB }{ }^{+}, \text {agsA::loxP. } \\
\text { Ptef1-agsB::pyroA, Ptef1-amyD::pyrG }\end{array}$ & This study \\
\hline$\Delta a g s B$ & biA1, pyrG89, wA3, argB2, pyroA4, veA1, ligD::ptrA, agsB::argB & (Yoshimi et al., 2013) \\
\hline $\operatorname{ags} A^{O E}$ & $\begin{array}{l}\text { biA1, pyrG89, wA3, argB2, pyroA4, veA1, ligD::ptrA, agsB::argB, Ptef1- } \\
\text { agsA::pyroA }\end{array}$ & This study \\
\hline $\operatorname{ags} A^{O E} \triangle a m y D$ & $\begin{array}{l}\text { biA1, pyrG89, wA3, argB2, pyroA4, veA1, ligD::ptrA, agsB::argB, Ptef1- } \\
\text { agsA::pyroA, amyD::pyrG }\end{array}$ & This study \\
\hline $\operatorname{ags}_{s} A^{O E} a m y D^{O E}$ & $\begin{array}{l}\text { biA1, pyrG89, wA3, argB2, pyroA4, veA1, ligD::ptrA, agsB::argB, Ptef1- } \\
\text { agsA::pyroA, Ptef1-amyD::pyrG }\end{array}$ & This study \\
\hline$\triangle a m y D-a m y D^{O E}$ & $\begin{array}{l}\text { biA1, pyrG89, wA3, argB2, pyroA4, veA1, ligD::ptrA, Aoarg } B^{+}, \text {amyD }:: p y r G, \\
\text { Ptef1-amyD::hph, pyrG }\end{array}$ & This study \\
\hline $\begin{array}{l}\triangle a m y D- \\
\operatorname{amy} D^{O E}(\triangle \mathrm{GPI})\end{array}$ & $\begin{array}{l}\text { biA1, pyrG89, wA3, argB2, pyroA4, veA1, ligD::ptrA, AoargB }{ }^{+}, \text {amyD::pyrG, } \\
\text { Ptef1-amyD( } \Delta \mathrm{GPI}):: h p h, p y r G^{-}\end{array}$ & This study \\
\hline $\begin{array}{l}\operatorname{ags} B^{O E} \triangle a m y D- \\
\operatorname{amy} D^{O E}\end{array}$ & $\begin{array}{l}\text { biA1, pyrG89, wA3, argB2, pyroA4, veA1, ligD::ptrA, agsB::argB, Ptef1- } \\
\text { agsA::pyroA, amyD::pyrG, Ptef1-amyD::hph, pyrG- }\end{array}$ & This study \\
\hline $\begin{array}{l}\operatorname{ags} B^{O E} \triangle a m y D- \\
\operatorname{amy} D^{O E}(\Delta \mathrm{GPI})\end{array}$ & $\begin{array}{l}\text { biA1, pyrG89, wA3, argB2, pyroA4, veA1, ligD::ptrA, agsB::argB, Ptef1- } \\
\text { agsA::pyroA, amyD::pyrG, Ptef1-amyD( } \triangle \mathrm{GPI}):: h p h, p y r G^{-}\end{array}$ & This study \\
\hline
\end{tabular}

$639 \quad{ }^{a}$ Fungal Genetic Stock Center, USA

640 Table 2. Molecular mass of alkali-soluble glucan in the cell wall.

\begin{tabular}{|c|c|c|c|c|}
\hline Sample & $M_{\mathrm{p}}{ }^{\mathrm{b}}$ & $M_{\mathrm{w}}{ }^{\mathrm{c}}$ & $M_{\mathrm{n}}^{\mathrm{d}}$ & $M_{\mathrm{w}} / M_{\mathrm{n}}$ \\
\hline WT AS2 $^{a}$ & $2 \square 830 \square 000 \pm 400 \square 000$ & $3 \square 510 \square 000 \pm 320 \square 000$ & $2 \square 280 \square 000 \pm 320 \square 000$ & $1.55 \pm 0.10$ \\
\hline$a m y D^{O E} \mathrm{AS} 2$, peak 1 & $2 \square 640 \square 000 \pm 400 \square 000$ & $3 \square 350 \square 000 \pm 660 \square 000$ & $2 \square 210 \square 000 \pm 700 \square 000$ & $1.57 \pm 0.25$ \\
\hline$a m y D^{O E} \mathrm{AS} 2$, peak 2 & $28 \square 100 \pm 1 \square 100$ & $41 \square 600 \pm 2 \square 600$ & $32 \square 900 \pm 300$ & $1.30 \pm 0.07$ \\
\hline$\triangle a m y D$ AS2 & $2 \square 910 \square 000 \pm 270 \square 000$ & $3 \square 540 \square 000 \pm 400 \square 000$ & $2 \square 390 \square 000 \pm 400 \square 000$ & $1.49 \pm 0.10$ \\
\hline $\operatorname{ags} A^{O E} \mathrm{AS} 2$ & $1 \square 930 \square 000 \pm 430 \square 000$ & $2 \square 410 \square 000 \pm 240 \square 000$ & $1 \square 260 \square 000 \pm 270 \square 000$ & $1.94 \pm 0.20$ \\
\hline $\operatorname{ags} A^{O E} a m y D^{O E} \mathrm{AS} 2$ & $2 \square 000 \square 000 \pm 120 \square 000$ & $2 \square 150 \square 000 \pm 170 \square 000$ & $1 \square 110 \square 000 \pm 110 \square 000$ & $1.94 \pm 0.05$ \\
\hline $\operatorname{ags}^{O E} \triangle a m y D$ AS2 & $2 \square 700 \square 000 \pm 300 \square 000$ & $3 \square 380 \square 000 \pm 230 \square 000$ & $2 \square 250 \square 000 \pm 130 \square 000$ & $1.50 \pm 0.05$ \\
\hline $\operatorname{ags}_{s} B^{O E} \mathrm{AS} 2$ & $623 \square 000 \pm 7 \square 000$ & $1 \square 144 \square 000 \pm 13 \square 000$ & $312 \square 000 \pm 5 \square 000$ & $3.67 \pm 0.03$ \\
\hline $\operatorname{ags}^{O E} a m y D^{O E} \mathrm{AS} 2$ & $169 \square 000 \pm 15 \square 000$ & $664 \square 000 \pm 14 \square 000$ & $140 \square 000 \pm 8 \square 000$ & $4.77 \pm 0.16$ \\
\hline$a_{g s} B^{O E} \triangle a m y D \mathrm{AS} 2$ & $877 \square 000 \pm 91 \square 000$ & $1 \square 435 \square 000 \pm 61 \square 000$ & $358 \square 000 \pm 19 \square 000$ & $4.01 \pm 0.12$ \\
\hline
\end{tabular}

641

${ }^{\mathrm{a}} \mathrm{AS} 2$, insoluble components after dialysis of the alkali-soluble fraction 
$642 \quad{ }^{\mathrm{b}}$ Peak molecular mass

$643{ }^{\mathrm{c}}$ Weight-average molecular mass

$644{ }^{\mathrm{d}}$ Number-average molecular mass

645 Values are mean \pm standard deviation of three replicates

646 Table 3. Molecular mass of alkali-soluble glucan in the cell wall of $\Delta a m y D$ - $a m y D^{O E}$

647 strains.

$648{ }^{\mathrm{a}} \mathrm{AS} 2$, insoluble components after dialysis of the alkali-soluble fraction

$649 \quad{ }^{\mathrm{b}}$ Peak molecular mass

$650 \quad{ }^{\mathrm{c}}$ Weight-average molecular mass

$651{ }^{\mathrm{d}}$ Number-average molecular mass

652 Values are mean \pm standard deviation of three replicates

653 Figure legends

654 Figure 1. Transcript levels of the $a m y D$ gene determined by quantitative PCR. Gene-

655 specific primers are indicated in Table S1. Error bars represent the standard deviation of the

656 mean calculated from three replicates. *Significant differences by Tukey's test $(P<0.05)$;

657 n.s., not significant.

658 Figure 2. Growth characteristics of $a m y D^{O E}$ and $\triangle a m y D$ strains in liquid culture. Upper

659 images, cultures in Erlenmeyer flasks; lower images, representative hyphal pellets of each

660 strain under a stereomicroscope. Scale intervals are $1 \mathrm{~mm}$.

661 Figure 3. Amount of glucose in AS2 fractions. Conidia $\left(5.0 \times 10^{5} / \mathrm{mL}\right)$ of each strain were

662 inoculated into $\mathrm{CD}$ medium and rotated at $160 \mathrm{rpm}$ at $37^{\circ} \mathrm{C}$ for $24 \mathrm{~h}$. Values show glucose

663 content of the AS2 fraction as a percentage of the total cell-wall weight. Error bars represent

664 standard error of the mean calculated from three replicates. *Significant difference by

665 Tukey's test $(P<0.05)$; n.s., not significant.

666 Figure 4. GPC elution profile of the AS2 fraction from the series of (A) $a g s A^{O E}$ strains,

667 (B) $\operatorname{ags}_{S}{ }^{O E}$ strains, and (C) wild type. The AS2 fraction from 24-h-cultured mycelia of each

668 strain was dissolved in $20 \mathrm{mM} \mathrm{LiCl} / \mathrm{DMAc}$. The elution profile was monitored by a refractive

669 index detector. Molecular masses (MM) of the glucan peaks were determined from a

670 calibration curve of polystyrene (PS) standards $(\bullet) . M_{\mathrm{w}}$, weight-average MM; $M_{\mathrm{n}}$, number-

671 average MM.

672 Figure 5. Localization of cell-wall polysaccharides of vegetative hyphae. Hyphae cultured

673 for $16 \mathrm{~h}$ were fixed and stained with AGBD-GFP for $\alpha$-1,3-glucan, fluorophore-labeled 
674 antibody for $\beta$-1,3-glucan, and fluorophore-labeled lectin for chitin. Scale bars are $10 \mu \mathrm{m}$.

675 Figure 6. Growth characteristics of $\triangle a m y D-a m y D^{O E}$ strains in liquid culture. Upper

676 images, cultures in Erlenmeyer flasks; lower images, representative hyphal pellets of each

677 strain under a stereomicroscope. Scale intervals are $1 \mathrm{~mm}$.

678 Figure 7. (A, B) Amounts of glucose and (C) GPC elution profiles of the AS2 fraction in

$679 \Delta a m y D-a m y D^{O E}$ strains. $(A, B)$ Conidia $\left(5.0 \times 10^{5} / \mathrm{mL}\right)$ of each strain were inoculated into

$680 \mathrm{CD}$ medium and rotated at $160 \mathrm{rpm}$ at $37^{\circ} \mathrm{C}$ for $24 \mathrm{~h}$. Values show glucose content of AS2

681 fraction as a percentage of the total cell-wall weight. Error bars represent standard error of the

682 mean calculated from three replicates. *Significant difference by Tukey's test $(* P<0.05)$;

683 n.s., not significant. (C) The AS2 fraction from 24-h-cultured mycelia of each strain was

684 dissolved in $20 \mathrm{mM} \mathrm{LiCl} / \mathrm{DMAc}$. The elution profile was monitored by a refractive index

685 detector. Molecular masses (MM) of the glucan peaks were determined from a calibration

686 curve of polystyrene (PS) standards ( $\square$ ). $M_{\mathrm{w}}$, weight-average MM; $M_{\mathrm{n}}$, number-average MM.

687 replicates. 


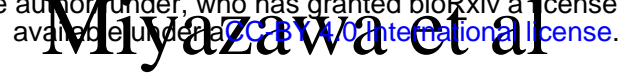
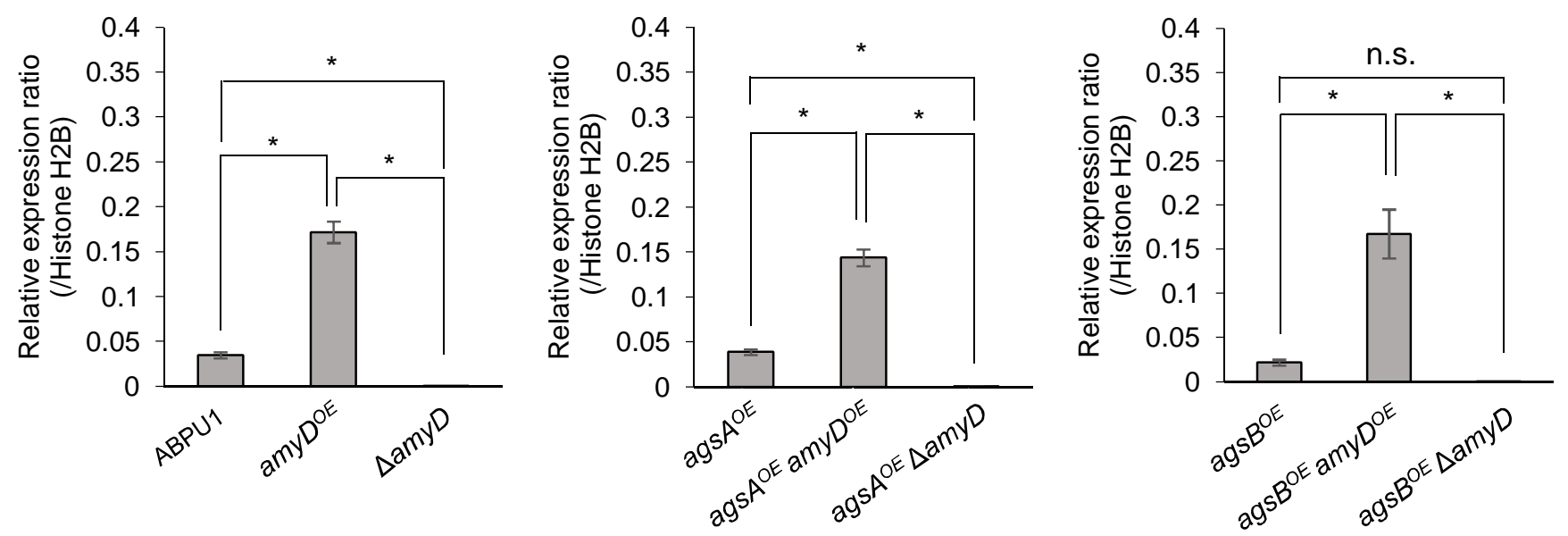
bioRxiv preprint doi: https://doi.org/10.1101/2021.11.24.469953; this version posted November 25, 2021. The copyright holder for this preprint (which was not certified by peer review) is the authorfunder, who has granted bioRxiv a ficense to display the preprint in perpetuity. It is made

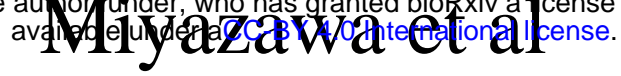

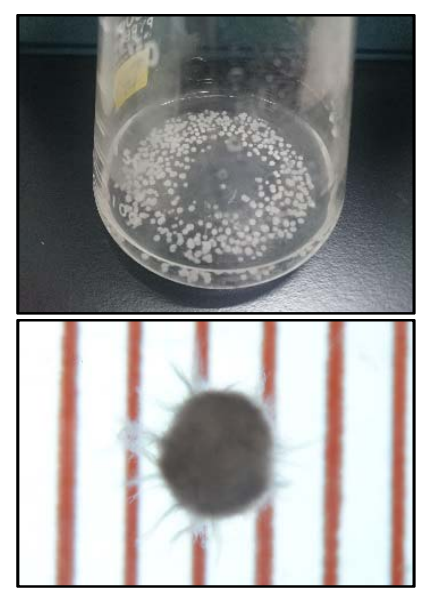

WT

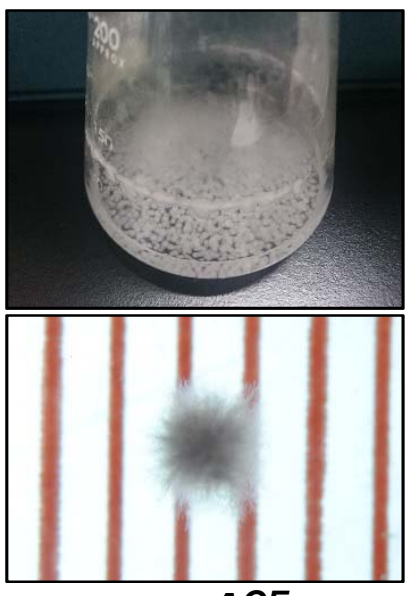

$\operatorname{ags} A^{O E}$

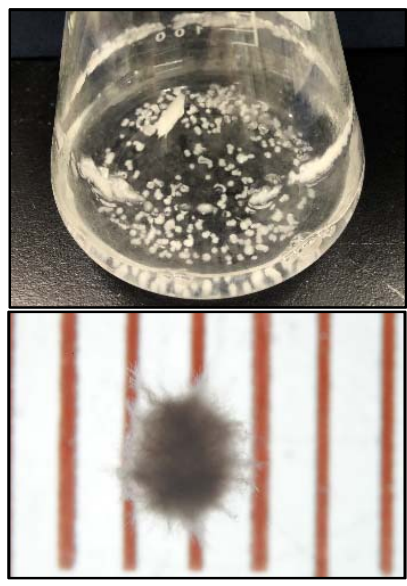

$\operatorname{ags} B^{O E}$

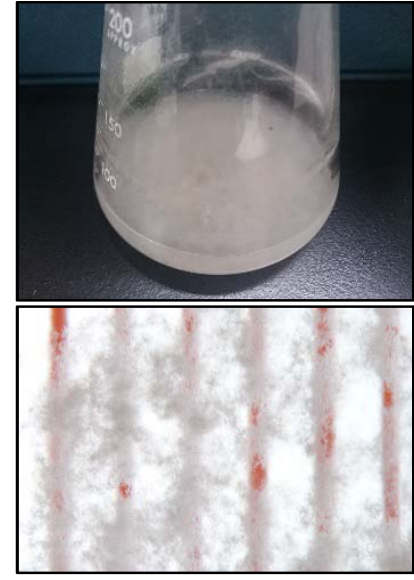

amyDOE
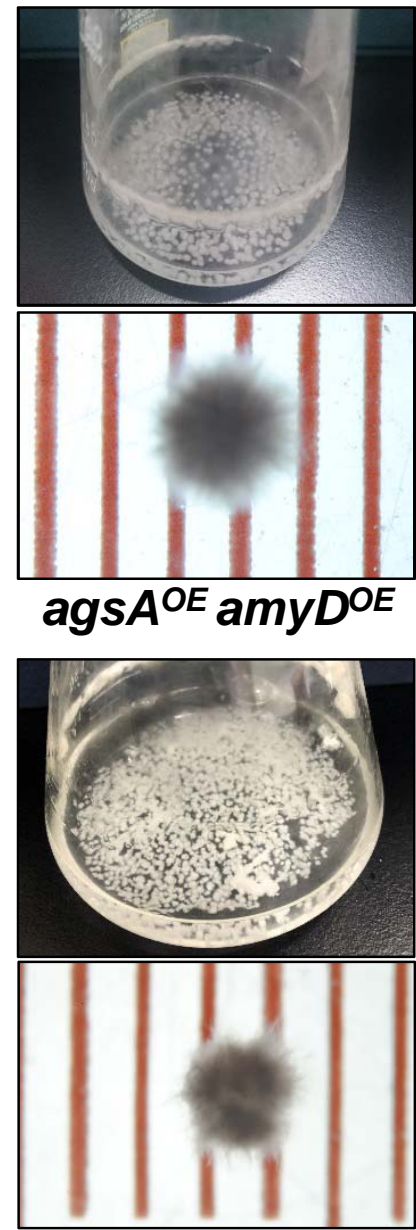

$\operatorname{ags} B^{O E}$ amy $D^{O E}$

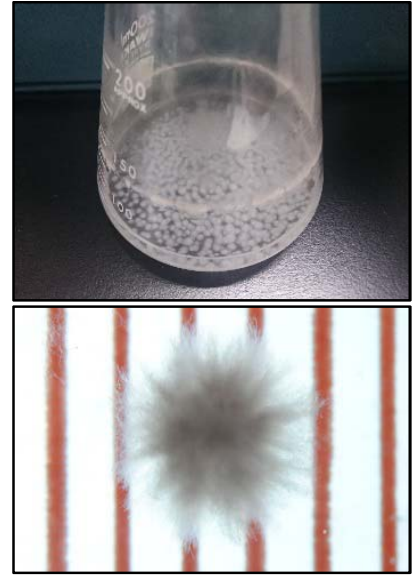

$\Delta a m y D$
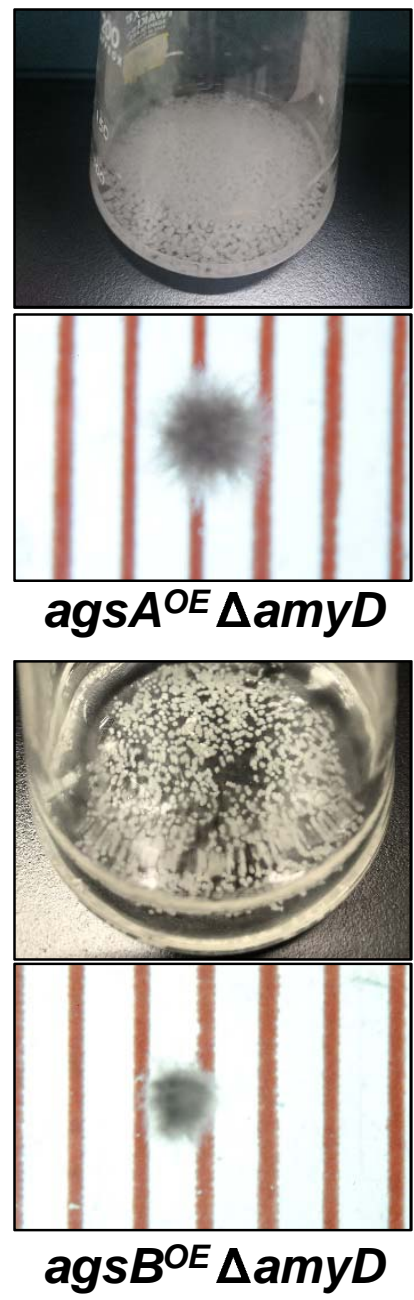

Figure 2 

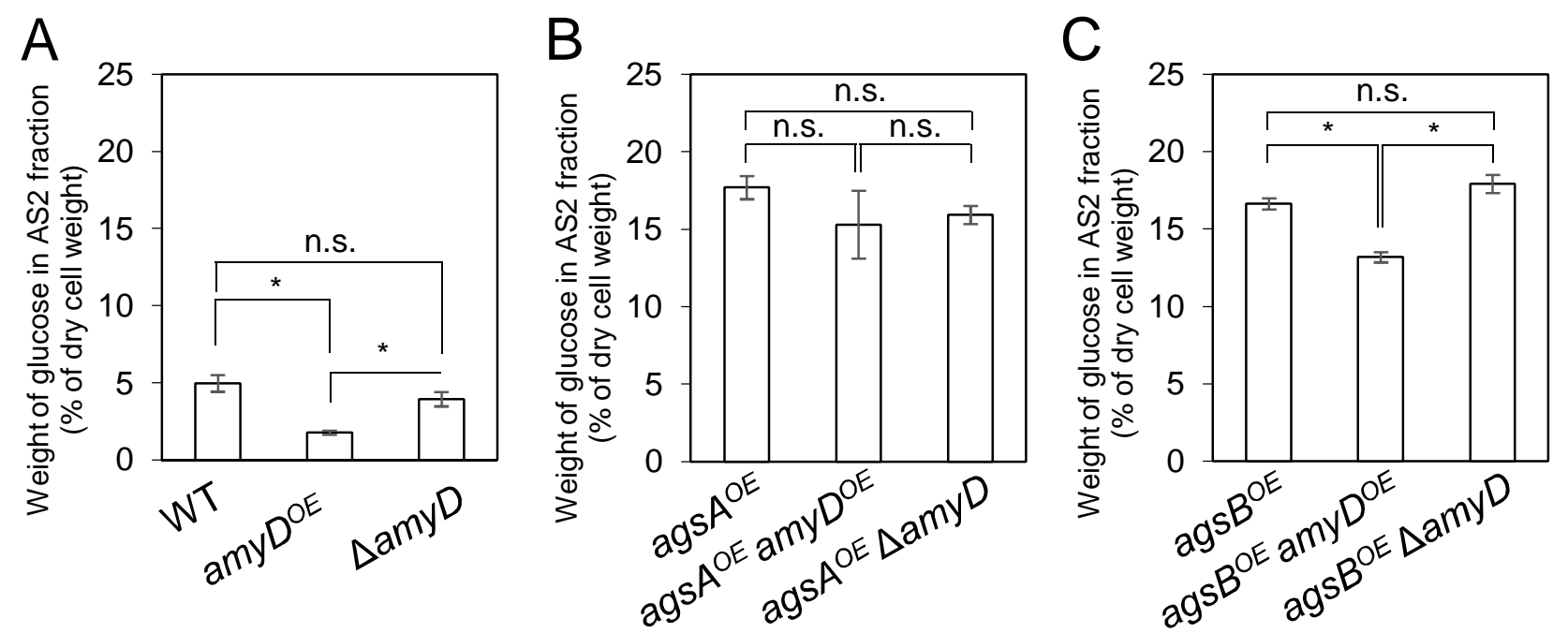


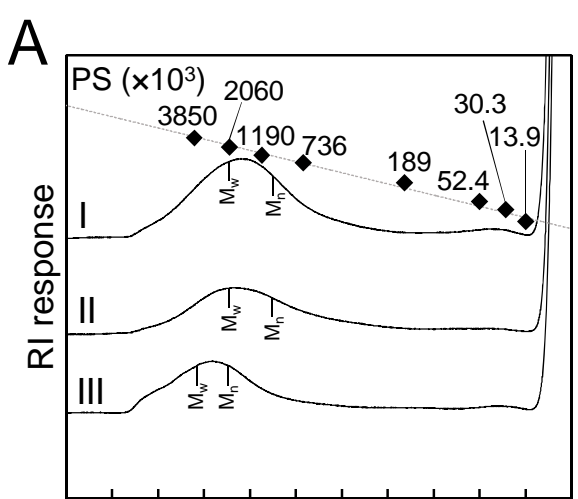

$8 \quad 9 \quad 10111213141516171819$

Retention time (min)

I, $\operatorname{ags} A O E$

II, agSAOE $a m y D O E$

III, agsA ${ }^{O E} \triangle a m y D$

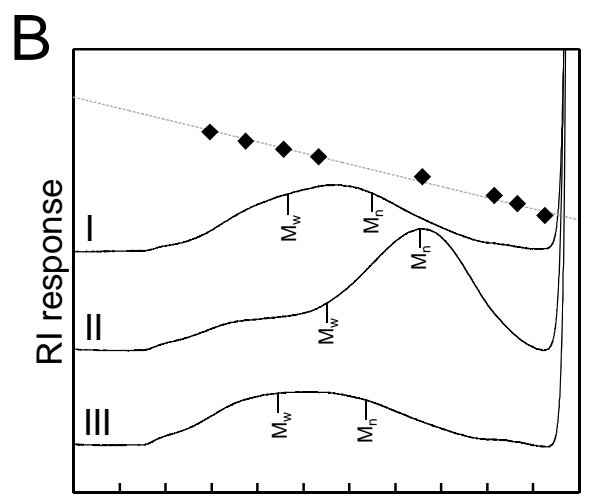

$8 \quad 9 \quad 10111213141516171819$ Retention time (time)

I, $\operatorname{agsB} B$

II, agsBOE $a m y D^{O E}$

III, agsB ${ }^{O E} \triangle a m y D$

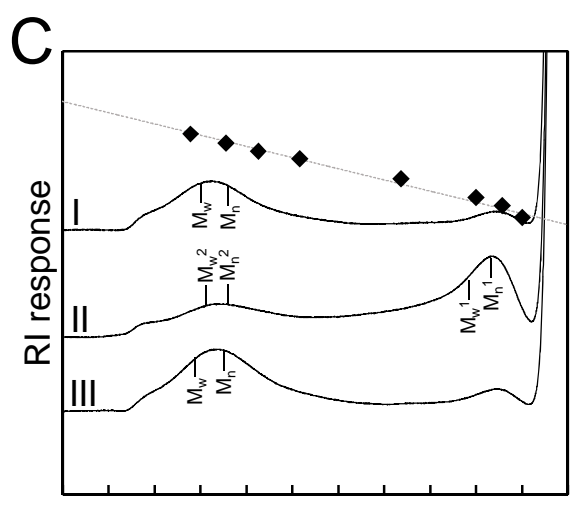

$8 \quad 9 \quad 10111213141516171819$ Retention time (min)

I, wild-type

II, amy ${ }^{O E}$

III, $\triangle a m y D$ 
bioRxiv preprint doi: https://doi.org/10.1101/2021.11.24.469953; this version posted November 25, 2021. The copyright holder for this preprint (which was not certified by peer review) is the authorffunder, who has granted bioRxiv a ficense to display the preprint in perpetuity. It is made

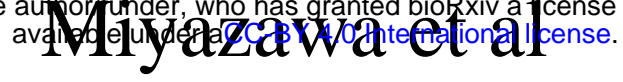

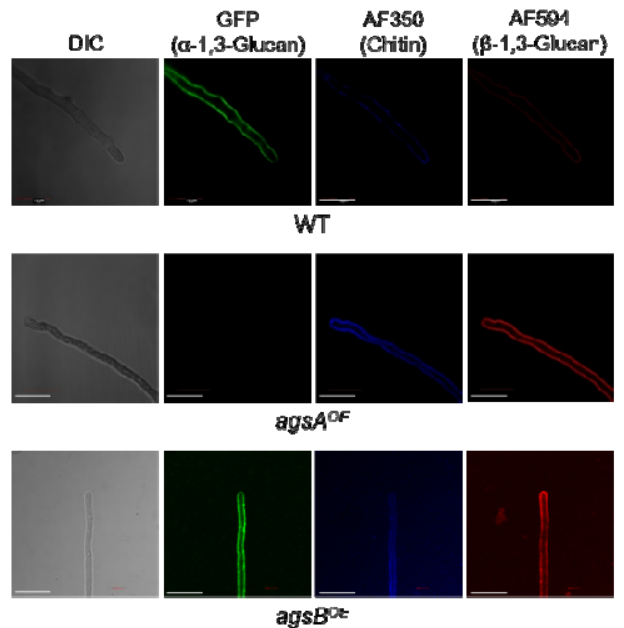

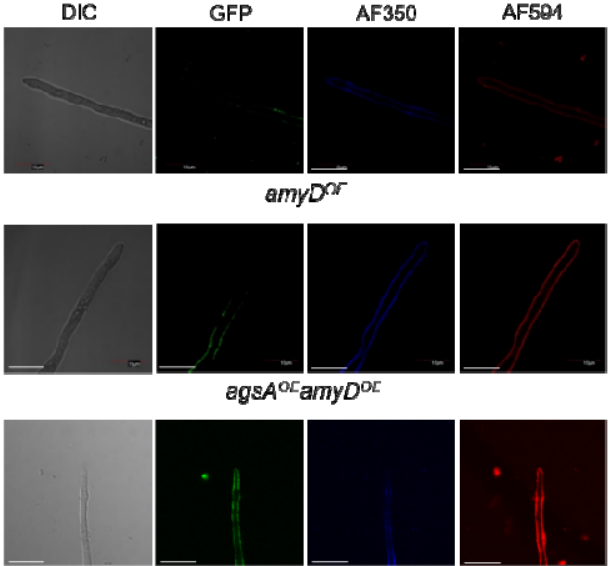

agsBoF $a m y D^{\mathrm{FF}}$
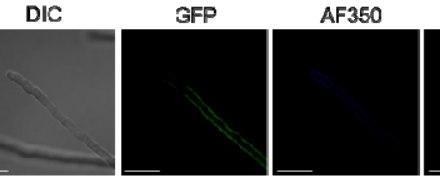

AF594

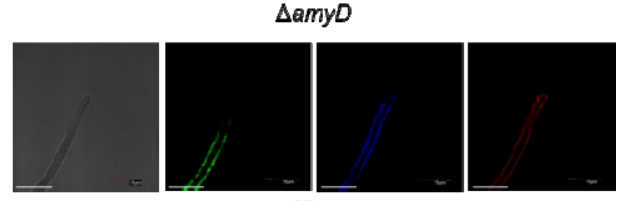

agsA ${ }^{\circ}{ }^{\triangle} \triangle a m y D$
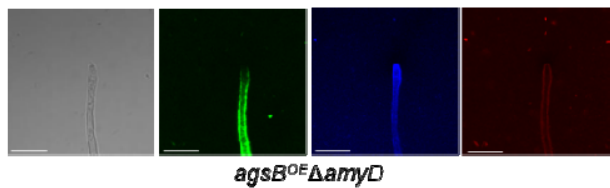

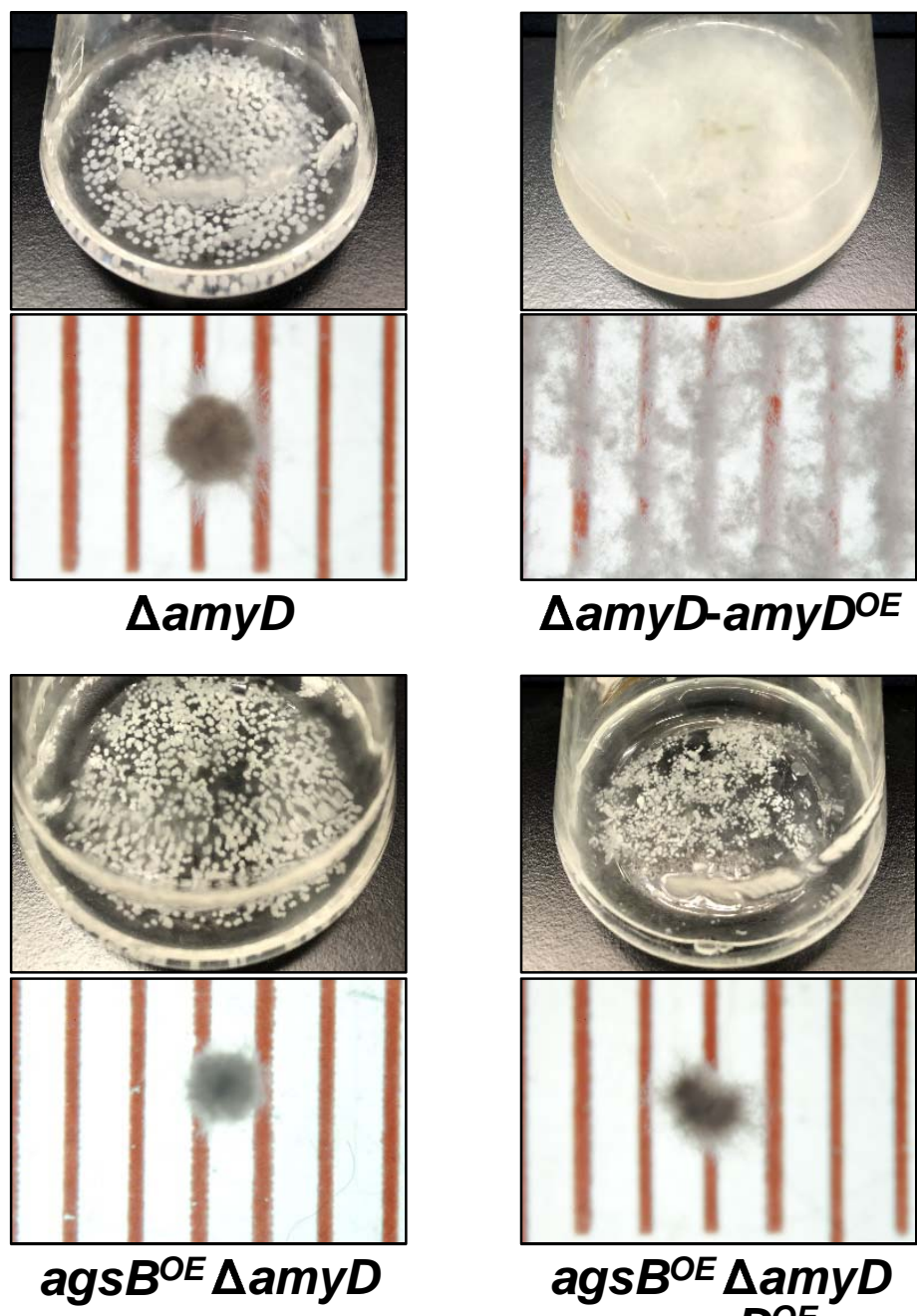

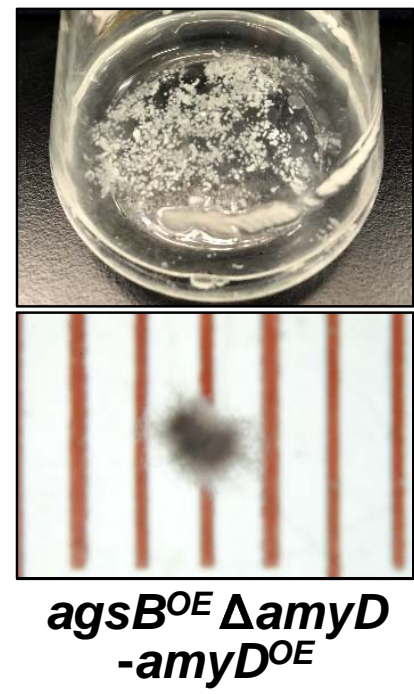

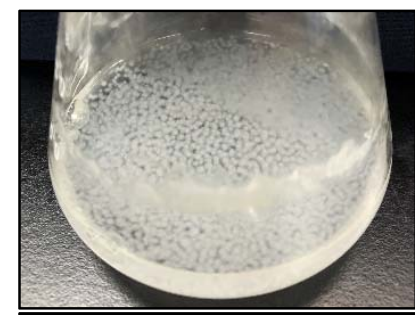

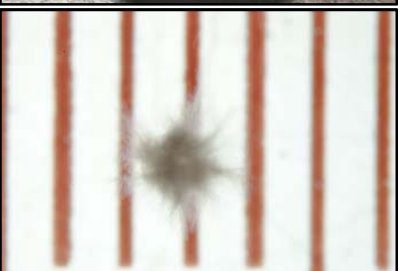

$\triangle a m y D-a m y D^{O E}(\Delta \mathrm{GPI})$

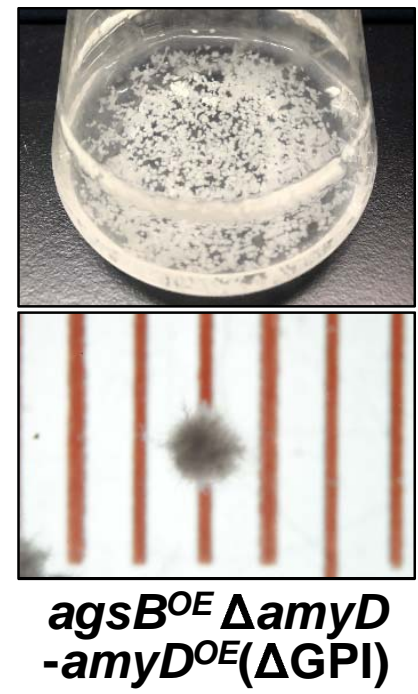

Figure 6 

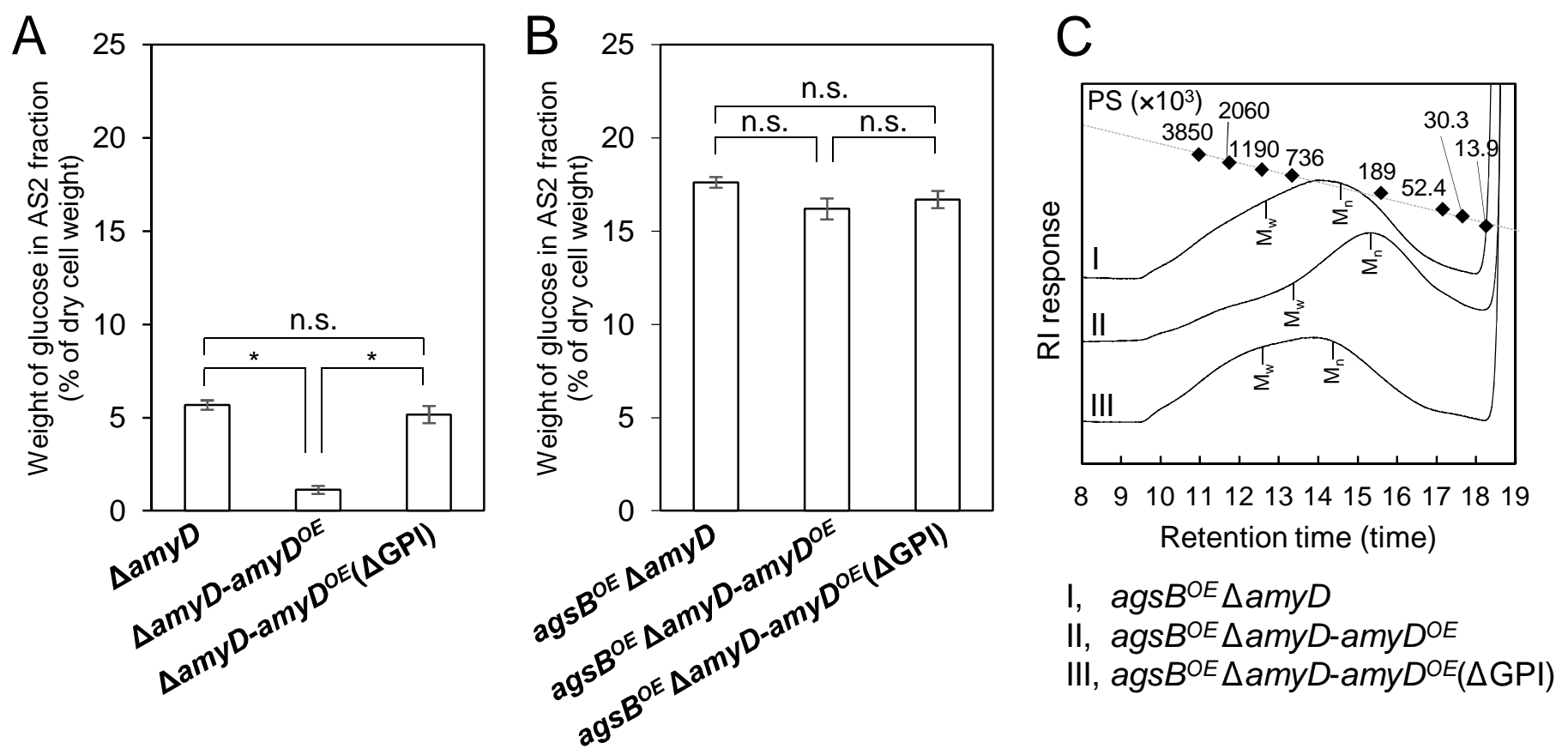